\title{
PARQUE TEMÁTICO, POPULARIZAÇÃO E PESQUISA AMAZÔNICA: A PROPOSTA DO BOSQUE DA CIÊNCIA/INPA
}

\author{
SAULO CÉZAR SEIFFERT SANTOS ${ }^{1}$ \\ ORCID: https://orcid.org/0000-0001-7890-1886 \\ MÁRCIA BORIN DA CUNHA ${ }^{2}$ \\ ORCID: https://orcid.org/0000-0002-3953-5198
}

\begin{abstract}
RESUMO: Os parques temáticos são espaços de entretenimento e de aprendizagem científico-cultural por meio das atividades educativas. Nos estados que compõem a Amazônia brasileira, há poucos museus de ciências do tipo clássico; em contrapartida, há ambientes abertos com a presença do verde e do vivo. Assim, o objetivo aqui foi realizar uma caracterização de um Espaço de Ciência e Tecnologia na Região Norte, com suas características amazônicas, que realiza investigação científica e que promove a popularização desta pesquisa junto às audiências em espaço de visitação física. Foi escolhida uma instituição de Ciência e Tecnologia que promove popularização científica das suas pesquisas - no caso, em Manaus (AM), o Instituto Nacional de Pesquisa da Amazônia (INPA) no seu espaço de extensão, o Bosque da Ciência. No início de 2018, foram recebidos documentos relacionados aos planejamentos, relatórios, solicitações de visitas e publicidade, com os quais se realizou uma análise de conteúdo do tipo temático. Os dados indicaram que a equipe de monitores realiza estágio curricular, com duração média de seis meses, ligado ao turismo e ao manejo florestal. Os visitantes são, na sua maioria, do público escolar da educação infantil e do ensino fundamental, e suas motivações de visita estão ligadas ao cultivo do enriquecimento cultural oriundo do espaço amazônico. Considera-se que o modelo de monitoria pode ser melhorado com ações de maior interiorização dos monitores na instituição, bem como com a adoção de uma visão do parque temático enquanto museu para uso de equipe multidisciplinar educativa para além do edutenimento, mas com uma visão de patrimônio amazônico.
\end{abstract}

Palavras-chave: educação não formal, museu de Ciências, Espaço de Ciência e Tecnologia, INPA.

\section{THEME PARK, POPULARIZATION AND AMAZONIC RESEARCH: THE PROPOSAL OF THE SCIENCE GROVE PARK/INPA}

\begin{abstract}
Theme parks are spaces for entertainment and scientific-cultural learning through cultural activities. In the states that make up the Brazilian Amazon there are few classic science museums, however, there are open environments with the presence of green and living. Thus, the objective was to characterize a Science and Technology Setting in the North Region, with its Amazonian characteristics,
\end{abstract}

\footnotetext{
${ }^{1}$ Universidade Federal do Amazonas (UFAM). Manaus, AM, Brasil. <sauloseiffert@ufam.edu.br>

${ }^{2}$ Universidade Estadual do Oeste do Paraná (UNIOESTE). Cascavel, PR, Brasil. <borin.unioeste@gmail.com> Educação em Revista|Belo Horizonte|v.38|e29448|2022
} 
which carries out scientific research and promotes the popularization of this research among audiences in physical visitation spaces. We chose a Science and Technology institution that promotes the scientific popularization of its research, in this case, in Manaus/AM, the National Institute for Research in the Amazon (INPA), in its extension space, the Science Grove Park. Between February and March 2018, we received documents related to planning, reports, requests for visits and advertising, in which we carried out a thematic content analysis. The data indicated that the team of monitors carries out a curricular internship, with an average duration of six months, linked to tourism and forest management, the visitors are mostly from the early childhood school audience and their visit motivations are linked to the cultivation of enrichment. cultural origin from the Amazonian space. We believe that the monitoring model can be improved with actions of greater internalization of monitors in the institution, adopting a vision of the theme park as a museum for the adoption of a multidisciplinary educational team in addition to education/entertainment, but a vision of Amazonian heritage.

Keywords: informal education, sciences museum, science and technology setting, INPA.

\section{PARQUE TEMÁTICO, POPULARIZACIÓN E INVESTIGACIÓN AMAZÓNICA: LA PROPUESTA DEL BOSQUE DE LA CIENCIA/INIA}

RESUMEN: Los parques temáticos son espacios de entretenimiento y aprendizaje científico-cultural a través de actividades culturales. En los estados que componen la Amazonía brasileña hay pocos museos de ciencia clásicos, sin embargo, hay ambientes abiertos con presencia de verde y vivo. Así, el objetivo fue caracterizar un Espacio de Ciencia y Tecnología en la Región Norte, con sus características amazónicas, que realiza investigación científica y promueve la divulgación de esta investigación entre las audiencias en espacios de visitación física. Elegimos una institución de Ciencia y Tecnología que promueve la popularización científica de su investigación, en este caso, en Manaus/AM, el Instituto Nacional de Investigaciones en la Amazonía (INPA), en su espacio de extensión, el Bosque de la Ciencia. Entre febrero y marzo de 2018 recibimos documentos relacionados con la planificación, informes, solicitudes de visitas y publicidad, en los que realizamos un análisis de contenido temático. Los datos indicaron que el equipo de monitores realiza una pasantía curricular, con una duración promedio de seis meses, vinculada al turismo y al manejo forestal. Los visitantes son, en su mayoría, del público escolar de la primera infancia y sus motivaciones de visita están vinculadas al cultivo del enriquecimiento cultural originado del espacio amazónico. Creemos que el modelo de seguimiento se puede mejorar con acciones de mayor internalización de los monitores en la institución, adoptando una visión del parque temático como museo para la adopción de un equipo educativo multidisciplinario además de "edutenimiento", pero una visión del patrimonio amazónico.

Palabras clave: educación no formal; Museo de Ciencia; espacio de ciencia y tecnología; INPA. 


\section{INTRODUÇÃO}

O Brasil é o país da América Latina que mais realiza divulgação científica e tecnológica (MAIA; BERGAMINI; CASTRO, 2018). Sendo um país de dimensões continentais, o desafio de realizar a divulgação científica está na mesma altura e complexidade em diferentes regiões, etnias, produções culturais e atividades econômicas.

Todavia, esse grande feito da nação popularizadora da Ciência e Tecnologia (CT) não é homogêneo entre as regiões brasileiras, tendo em vista que há grandes desigualdades econômicas, sociais e de produção de CT, país afora. Assim, destaca-se aqui a Região Norte do Brasil, que reflete essa desigualdade e busca avançar para superar anos de atraso e exploração econômica e social, pois que esta foi a última região brasileira a ser integrada ao Brasil por via terrestre, como também data de poucas décadas que o Norte recebe atenção e atendimento consistente de políticas públicas em educação, economia e desenvolvimento social (ARAGON, 2013).

As instituições científicas da Região Norte são de número muito pequeno em comparação com as outras regiões e possuem, historicamente, pouco tempo no processo de construção de uma tradição de pesquisa. Atualmente, são menos de cinco instituições de pesquisa com mais de 50 anos na Região Norte (SEIFFERT-SANTOS; CUNHA, 2020). Isso impacta diretamente a divulgação dessa produção científica e tecnológica pelo número rarefeito de instituições e, por conseguinte, o volume de grupos de pesquisas engajados numa região que ocupa quase $50 \%$ do território brasileiro.

Essa região é conhecida como parte da Amazônia, um signo bastante ventilado com vários sentidos e com significado polifônico. Para isso, podem-se elencar algumas marcas próprias, que, segundo Fonseca (2011) e Loureiro (2015), são: maior floresta tropical do mundo, maior biodiversidade terrestre do planeta, uma das maiores bacias de água doce do mundo; apresenta um mosaico de diversidade cultural entre povos indígenas, ribeirinhos e regiões rurais e urbanas, distribuídas de forma distinta no território - há povos vivendo em isolamento na floresta e outros em complexos urbanos de conurbação. Logo, a sua investigação científica reflete e refrata essas marcas e condições.

Assim, a Divulgação Científica e Tecnológica (doravante designada por DC) processa-se por meios diversos. Seiffert-Santos (2020b), com base em Bueno (2002) e Nascimento (2010), informa que:

[...] [a DC] é vista como responsável pela disponibilização da informação científica e tecnológica ao público amplo, escolar e não escolar, no formato do jornalismo científico e no formato de popularização da Ciência para a formação cidadã e crítica (SEIFFERT-SANTOS, 2020b, p. 419).

Das formas de DC, o Museu de Ciências e seus análogos/similares (jardins botânicos, parques, zoológicos e outros) são instituições ou Espaços de Ciência e Tecnologia (ECT) com emprego de popularização dessas produções da cultura científica como modalidade própria e características distintas (CGEE, 2019). São concomitantemente instituições de recepção de visitas que normalmente apresentam o seu projeto de educação não formal (museal) próprio (MARANDINO, 2001; PALHARES, 2009; CGEE, 2019).

Como mencionado anteriormente, a Região Norte do Brasil apresenta o menor número de instituições; isso se reflete nos ECT, com somente 11 Museus e Centros de Ciências, entre os 268 cadastrados no guia Museus e Centros de Ciências presentes no "Catálogo Centros e Museus de Ciências do Brasil 2015” (ABCMC, 2015). Situados especificamente nos estados do Amapá, Amazonas e Pará, alguns desses ECTs são: Centro de Pesquisa Museológica - Museu Sacaca (Macapá/AP); Bosque da Ciência/INPA (Manaus/AM); e Museu Zoobotânico Emílio Goeldi (Belém/PA). Trata-se de instituições com ênfase nas ricas exposições sobre a biodiversidade e os elementos antropológicos amazônicos (mais detalhes serão apresentados na próxima seção). Assim, observa-se, nesses exemplos, que a marca regional amazônica de DC em ECT são locais abertos, associados à floresta e a seus elementos, em especial ao vivo.

A título de exemplo de pesquisa com ambientes abertos que recebem visitantes, Suescun et al. (2012), que analisaram o Jardim Botânico do Rio de Janeiro, descreveram a experiência como uma totalidade não percebida imediatamente; contudo, entendem que há uma mediação pela noção espacial proporcionada pelo informativo (mapa do jardim). A experiência vivida nesse espaço compreende ainda a luz do ambiente, que ativa a dimensão visual (cores e características em função dos horários e estações 
do ano que são percebidas); a audição, com os cantos dos pássaros e outros elementos naturais; e o aroma das frutas, flores e árvores. A essa caracterização, as autoras incorporaram a linguagem expográfica da museografia, em artefatos verbais e iconográficos, para complementar o ambiente em um sistema de integração, e não de destaque aos outros elementos do jardim. As autoras o denominaram como "jardim temático", mas há outro termo usado - o Parque Temático.

O termo Parque Temático não é frequente nas pesquisas em educação em Ciências e espaços de educação não formal. Entretanto, é um termo utilizado no livro organizado por Silvério Crestana e colaboradores (2001), diretor da Estação Ciência nessa época - uma divisão de divulgação científica e tecnológica da Universidade de São Paulo (USP) -, intitulada "Educação para a Ciência: Curso para treinamento em Centros e Museus de Ciência". Na seção de Parques Temáticos do livro, aberta por Alain Baldacci (representante da Associação Mundial de Parques), embora não se defina o que seja um parque temático, o termo é relacionado ao ambiente, à atividade e à visita com interatividade e entretenimento para proporcionar uma experiência leve e suave aos visitantes, além de introduzir o neologismo "edutenimento", no caso da temática de Ciência. Essa seção apresenta, como parques temáticos, o Parque de Ciência, na temática Saúde da Fiocruz, no Rio de Janeiro; o Parque da Água Branca, em São Paulo; a Casa da Ciência/Bosque da Ciência do INPA, em Manaus; o Parque de Ciências, em Belém; e o Parque de Ciências da Terra e do Universo, em São Paulo.

Todavia, Bonatto (2001), em seu texto sobre o Parque de Ciência da Fiocruz, define que o Parque Temático está associado aos parques de diversão. Assim, o que esses parques têm em comum é a oferta de atividades de entretenimento com aspecto educativo, o edutenimento. Considerando-se esse critério, os parques temáticos como o Bosque da Ciência são um local de lazer para os visitantes, preservando uma área de fragmento florestal e, ao mesmo tempo, promovendo a educação ambiental (BUENO, 2001).

Dessa forma, o objetivo deste trabalho é fazer uma caracterização de um ECT na Região Norte, o qual realiza pesquisa científica e promove o seu espaço para popularizar parte dessa pesquisa junto às audiências visadas pela instituição. Essa caracterização parte das informações sobre as exposições e os documentos de solicitação de visita e de organização funcional do parque. No caso, o parque temático selecionado para esta análise foi o Bosque da Ciência do Instituto Nacional de Pesquisa da Amazônia (INPA).

Com isso, tem-se a intenção de reconhecer traços favoráveis à constituição da educação não formal em Ciência e Tecnologia em um ECT de contexto amazônico.

\section{REFERENCIAL TEÓRICO}

Foi feita uma associação dos Espaços de Ciência e Tecnologia (ECT) com os espaços de educação não formal científico e tecnológico, caracterizando-os como formas inclusas ou análogas na categoria de Museus de Ciências (ABCMC, 2015). Dessa forma, os estudos de educação não formal empregados nos Museus de Ciências podem ser comparados com os projetos educativos de ambientes abertos institucionais.

Considera-se que os museus de Ciências possuem "modalidades" de educação não formal (CHAGAS, 1993). Em sua recente atualização da definição de museu, o Conselho Internacional de Museus (International Council of Museums - ICOM) estabeleceu que:

Os museus são espaços democratizantes, inclusivos e polifônicos para um diálogo crítico sobre o passado e o futuro. Reconhecendo e abordando os conflitos e desafios do presente, eles mantêm artefatos e espécimes em confiança para a sociedade, salvaguardam diversas memórias para as gerações futuras e garantem direitos iguais e acesso igual ao patrimônio para todas as pessoas. Os museus não são lucrativos. Eles são participativos e transparentes, e trabalham em parceria ativa com e para diversas comunidades para coletar, preservar, pesquisar, interpretar, exibir e melhorar a compreensão do mundo, visando contribuir para a dignidade humana e a justiça social, a igualdade global e o bem-estar planetário (ICOM, 2019, online, tradução livre) ${ }^{3}$.

\footnotetext{
${ }^{3}$ ICOM. Disponível em: https://icom.museum/en/activities/standards-guidelines/museum-

definition/?fbclid=IwAR2OIpsWyJLfce1Bej1H1otK9a06e5i358gTaX36rjmRyty 31PbIeclapZc. Acesso em: 6 ago. 2019. Educação em Revista|Belo Horizonte|v.38|e29448|2022
} 
Em termos legais, a definição de museu, fundamentada no artigo $2^{\circ}$, incisos IX e X, do Decreto Federal $n^{\circ}$ 8.124/2013, é objeto da Portaria n ${ }^{\circ}$ 422/2017, do Ministério da Cultura, por meio do Instituto Brasileiro de Museus, que dispõe sobre a Política Nacional de Educação Museal, apresentando as definições de museu e de processo museológico:

[...] - museu - instituição sem fins lucrativos, de natureza cultural, que conserva, investiga, comunica, interpreta e expõe, para fins de preservação, estudo, pesquisa, educação, contemplação e turismo, conjuntos e coleções de valor histórico, artístico, científico, técnico ou de outra natureza cultural, abertos ao público, a serviço da sociedade e de seu desenvolvimento; - processo museológico - programa, projeto e ação em desenvolvimento ou desenvolvido com fundamentos teórico e prático da museologia, que considere o território, o patrimônio cultural e a memória social de comunidades específicas, para produzir conhecimento e desenvolvimento cultural e socioeconômico. (BRASIL, 2017, n.p).

Segundo a definição do ICOM e da Portaria no 422/2017, o museu e o processo museológico têm a função de conservar e educar para o patrimônio cultural e devem ser acessíveis aos cidadãos. A mesma portaria também informa a necessidade de uma equipe multidisciplinar para o projeto de educação museal (educação não formal), com abordagem de comunicação e interação com os públicosalvo da instituição.

Segundo Wagensberg, a interação com o visitante pode ser:

[...] para estimular de acordo com o máximo de três tipos de interatividade com o visitante: 1) manual ou provocador de emoção - Interatividade Hands-On - em mãos; 2) emoção mental ou inteligível - Interatividade $\mathrm{Minds-On}$ - na mente; 3) emoção cultural ou cultural - Interatividade Heart-On - no coração. O terceiro é altamente recomendado, o primeiro é muito conveniente e o segundo, simplesmente essencial. Interatividade significa conversa. Experimentar é conversar com a natureza. Refletir é estar falando consigo mesmo. Um bom canto do museu também desencadeia conversas entre os visitantes. (WAGENSBERG, 2001, p. 23, tradução livre) ${ }^{4}$.

Para Wagensberg (2001), a interação realiza-se das seguintes formas: pela conversa; consigo mesmo; pela manipulação de botões (o que acontecerá se aperto isto?) - hands-on; pelas questões e atividades do cotidiano em pensar e se emocionar com as respostas e reflexões por meio da inteligibilidade mental - minds-on; e pelas atividades para a distinção das identificações culturais, daquilo que é fora da cultura própria de cada um, e da promoção da emoção cultural - heart-on.

Ressalta-se, conforme Pavão e Leitão (2007), que há uma extrapolação, em especial com os Centros de Ciências, na interação hands-on, por vezes confundida com a própria interatividade, inviabilizando outras interações, em especial as com o monitor/mediador, e a experiência social do outro (visitante de audiência). Por outro lado, na tradicional contemplação, apesar de não envolver interação física, há interação do discurso externo com o discurso interno do sujeito do conhecimento (VOLÓCHINOV; BAKHTIN, 2017 [1927]); o sujeito não manipula fisicamente, mas observa. Aqui, há de convir que se possa convergir para um grau monológico; mas, na perspectiva cultural, a interpretação não pode ser generalizada, pois, a partir da filosofia hermenêutica, ela é uma construção pessoal, podendo ocorrer várias negociações de significados entre o discurso interno do sujeito e os discursos da exposição.

No tocante a essa estratégia comunicativa, percebe-se que os museus de Ciências são marcados historicamente. McManus (1992), Padilla (2001) e Friedman (2010) chamam de 'gerações de museus de Ciências' determinadas formas e estratégias comunicativas de expressar um dialogismo de divulgação científica, pois são grupos relativamente homogêneos no teor comunicativo. Cada um deles possui um enfoque reconhecido nos momentos históricos dos museus de CT. Esses enfoques são delimitados usualmente por três gerações: $1^{a}$ Geração - Museus de História Natural (coleções de acervo natural conservado); $2^{\mathrm{a}}$ Geração - Museus da Indústria e Tecnologias (acervo histórico de artefatos tecnológicos); $3^{\mathrm{a}}$ Geração - Centros de Ciências (acervo de experimentos de Ciências). Entretanto, as

\footnotetext{
${ }^{4}$ [...] para estimular según el máximo de las siguientes tres clases de interactividad con el visitante: 1) Interactividad manual o de emoción provocadora (Hands-On) 2) Interactividad mental o de emoción inteligible (Minds-On) 3) Interactividad cultural o de emoción cultural (Heart-On) La tercera es muy recomendable, la primera es muy conveniente, y la segunda, sencillamente imprescindible. Interactividad significa conversación. Experimentar es conversar con la naturaleza. Reflexionar es conversar con uno mismo. Un buen rincón de museo dispara también la conversación entre los visitantes.
} 
diferenças entre essas gerações não se restringem somente ao enfoque, uma vez que são influenciadas por uma complexa relação de condições materiais, históricas e econômicas. Para um estudo detalhado das condições históricas de desenvolvimentos dos enfoques, sugere-se a leitura de McManus (1992).

Há uma ideia de terceira geração tardia, ou quarta geração, que, segundo Padilla (2001), são instituições que se caracterizam por levar em consideração as condições contemporâneas de globalização (pelo alto grau de trabalho competente e integrado; pela passagem dos artefatos de alto volume para outros de alto valor; pela informatização; pela integração entre tecnologia, conhecimento e habilidades; por inovações em práticas educativas; pelo uso de esquemas laborais; pela personalização da experiência de visita; e pela interação entre temas globais e locais).

Essas demandas tanto podem ser relacionadas aos parques temáticos, segundo Londoño, Solbes e Guisasola (2009), a exemplo dos parques da Disney (privados e lucrativos) ${ }^{5}$, como também aos parques de conservação e lazer, com quadros temáticos que não possuem um único foco, ou um predominante, mas oferecem várias formas de entretenimento com informação.

Atualmente, com o aparecimento dos parques temáticos com alta tecnologia e de expressivos empreendimentos de grupos privados, ou até com a participação de governos, há constituições enunciativas polifônicas e pluriestilísticas que ocorrem desde a presença de jardins zoobotânicos até a de exposições com interação com inteligência artificial (SABIESCU; CHARATZOPOULOU, 2018). Entende-se que o espírito do tempo atual contempla uma grande diversidade nos aspectos culturais, econômicos e ideológicos, que se manifesta pelas formas de expressão dos grupos de pensamentos científicos próprios e com tratamento e apresentação específicos do contexto local. Assim, entende-se como parques temáticos não só os empreendimentos lucrativos e de alta tecnologia, mas também os ambientes com múltiplos focos, que contribuem para o lazer e o conhecimento dos visitantes.

Assim, as ações de divulgação em CT na Região Norte, por meio de instituições de espaços de educação não formal (ECTs), são novas, mas contam com uma história nada recente, pelo fato de existir na Amazônia o mais antigo zoológico do Brasil. Contudo, há poucas outras instituições não formais, em especial fora do estado do Pará. Não obstante, esse número começou a mudar recentemente.

De início, enfocam-se os dados da última pesquisa de percepção pública da Ciência realizada pela CGEE (2019) sobre o acesso aos espaços de CT. A pesquisa mostra que os zoológicos, os jardins botânicos e os parques ainda são os mais visitados pela população, correspondendo a $25 \%$ das respostas, como pode ser visto na Figura 1.

Figura 1 - Percentual dos entrevistados segundo a declaração de visitação a espaços de difusão científicocultural e participação em eventos de Ciência e Tecnologia, em 2006, 2010, 2015 e 2019.

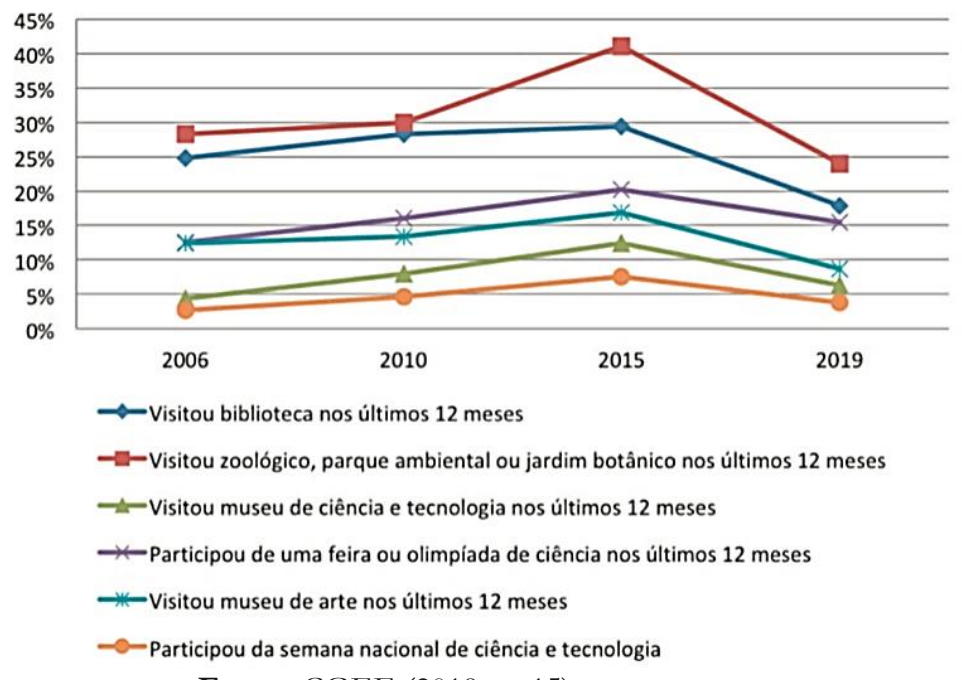

Fonte: CGEE (2019, p. 15).

\footnotetext{
${ }^{5}$ Em 2019, a definição de museu foi reelaborada, caracterizando-o como ‘não lucrativo' e, nesse caso, não contemplando os Parques Temáticos da Disney e de outras empresas, mesmo que possuam atividades ligadas ao patrimônio cultural e à conservação.
} 
A preferência por esses espaços abertos com objetos biológicos ou com elementos ambientais regionais vem-se mantendo nas quatro últimas consultas de âmbito nacional. Polino (2015, p. 103), em sua pesquisa sobre percepção pública da CT em documentos oficiais de alguns países da América Latina, informa que a maior parte das populações opta por visitar parques ambientais ${ }^{6}$, jardins botânicos e zoológicos, demonstrando não se tratar de fenômeno exclusivo do Brasil:

- Argentina - pesquisa em 2012 - Visitas a um zoológico, jardim botânico ou aquário $(26,3 \%)$; e visitas a um parque nacional ou reserva natural $(24,7 \%)$;

- Colômbia - pesquisa em 2012 - Visitas a um parque natural (48,4\%); e visitas a um zoológico ou aquário (40,1\%);

- México - pesquisa em 2011 - Visitas a um zoológico ou aquário (43,4\%);

- Uruguai - pesquisa em 2011 - Visitas a um zoológico, jardim botânico, aquário, reserva ou planetário $(30 \%)$.

Apesar dessa preferência brasileira e latino-americana, a Região Norte do Brasil conta com o menor número de instituições. De um total de 3.118 museus registados no Instituto Brasileiro de Museus (2011), somente 152 (4,8\%) estão na Região Norte, e somente 19 dessas instituições são categorizadas em Ciências Naturais e História Natural.

A mudança do quadro de ausência de ECTs pode acontecer a partir do aumento dos programas de pós-graduação em educação e ensino de Ciências na Região Norte, com foco nos estudos pedagógicos escolares em locais fora da sala de aula, com elevação especial no número de pesquisas a partir de 2008 (SEIFFERT-SANTOS; FACHÍN-TERÁN, 2013). Isso se deve ao fato de não haver museus de história natural e centros de ciências na maioria dos estados da Região Norte, com exceção do Pará e do Amapá. Logo, essas pesquisas buscaram espaços institucionais onde ocorre o processo de DC e instituições congêneres ao museu que possibilitam temas ligados ao ensino de Ciências e ao contexto local (elementos culturais, antropológicos e florestais amazônicos etc.). Merecem destaque os grupos de pesquisa nas linhas de investigação relacionadas ao espaço não formal dos estados do Pará, Amazonas e de Roraima.

As atividades de pesquisa em museologia no estado do Pará são as mais antigas e consolidadas no País, resultado da criação do primeiro jardim zoológico e segundo centro de pesquisa brasileiro, em 1885, o Museu Paraense Emílio Goeldi (MPEG), tendo o Parque Zoobotânico sido registrado em 1887 (SANJAD et al., 2012).

Segundo Sanjad et al. (2012) e Florez, Sanjad e Okada (2018), as coleções vivas e a distribuição no espaço aberto desenvolvem uma musealização e um tipo de atividade museal com as seguintes proposições: a) o arranjo segundo o qual as coleções vivas são expostas colaboram para a compreensão da relação entre o homem e a natureza em diferentes períodos históricos; b) o processo de musealização ocorre de forma diferente nos jardins botânicos em relação aos museus de história natural, em decorrência da imobilidade do acervo (plantado); c) o potencial de comunicação dos museus de natureza é relacionado à fixidez ou imobilidade da coleção, e ao dinamismo das transformações naturais verificadas no decorrer do tempo (o ciclo natural dos organismos e as estações do ano).

\section{O Bosque da Ciência/INPA a partir das pesquisas}

Seiffert-Santos e Cunha (2018) realizaram um levantamento das investigações acerca do Bosque da Ciência/INPA, local desta pesquisa. Os trabalhos destacaram a fundação do INPA, em 19547, e a criação do Bosque da Ciência, em 1995, com um ambiente físico de 13 hectares, localizado na Zona

\footnotetext{
${ }^{6} \mathrm{O}$ uso do termo parque não coincide com o conceito de parque temático, pois o parque temático tem um foco lúdico. Os parques ambientais, nacionais ou naturais são termos jurídicos ligados à legislação ambiental para a pesquisa, a conservação e/ou o desenvolvimento sustentável. Todavia, há uma aparente aproximação: todos eles são ambientes abertos e com acesso à biodiversidade e às diversas dinâmicas humanas.

${ }^{7}$ O INPA instalou-se em Manaus sob a direção do Conselho Nacional de Pesquisa (CNPq), em 27 de junho de 1954; em 1987, foi transformado em órgão de administração direta, com autonomia administrativa e financeira, vinculado à Secretaria de Ciência e Tecnologia. Atualmente, o INPA está vinculado ao Ministério de Ciência, Tecnologia, Inovação e Comunicação, disposto no Decreto no 8.877/2016, sendo uma Instituição de Ciência e Tecnologia (ICT) nos termos da Lei n 10.973/2004, regulamentada pelo Decreto $\mathrm{n}^{\circ}$ 5.563/2005, e tendo por finalidade/missão "gerar e disseminar conhecimentos e tecnologias, bem como capacitar recursos humanos para o desenvolvimento da Amazônia”.
} 
Centro-Sul de Manaus (AM), definindo-o como espaço socioeducativo para promoção da divulgação científica e da educação ambiental para visitantes da comunidade e das escolas.

Em seu site ${ }^{8}$, a instituição destaca que os seus objetivos são: desenvolver e promover o programa do INPA para difusão tecnológica, científica e de inovação; e oferecer à população local uma opção de lazer que possa contribuir para sua educação cultural e ambiental.

Os trabalhos ressaltam a implementação do Programa Circuito da Ciência, em 1999, ligado às atividades de extensão, baseadas na aprendizagem pela exibição e ludicidade. Tais atividades são destinadas a estudantes da educação infantil e fundamental, com tarefas variadas, envolvendo o uso dos recursos hídricos, pirogravuras recicladas, saúde bucal, nutrição e rotulagem de alimentos, invertebrados terrestres, mamíferos aquáticos, vida do gavião real, malária e dengue, tecnologias sociais das abelhas e sapos, dentre outros (NORONHA; SANTOS; CARVALHO, 2013; BATISTA; VASCONCELLOS; FACHÍN-TERÁN, 2015; MARTINS et al., 2015; MOTA; FACHÍN-TERÁN; GONZAGA, 2015; SILVA et al., 2015).

As três estações mais citadas nas pesquisas são o tanque do peixe-boi - Trichechus inunguis (Figura 2); o recanto das ariranhas - Pteronura brasiliensis -; e o recanto das inajás (palmeira, Attalea maripa), embora também mereçam destaque as trilhas, ricamente ocupadas por vegetação, com placas informativas, em que os animais, como os poraquês (peixe-elétrico, Electrophorus electricus), e as plantas aquáticas diversas são os protagonistas (SEIFFERT-SANTOS; CUNHA, 2018).

Figura 2 - Vivências sensoriais, no tanque do Peixe-boi, conduzidas por pesquisadores e professores junto a crianças da educação infantil. À esquerda, a criança, por meio dos fones de ouvido, ouve as vocalizações do animal; à direita, as crianças podem tocar no couro de um filhote.

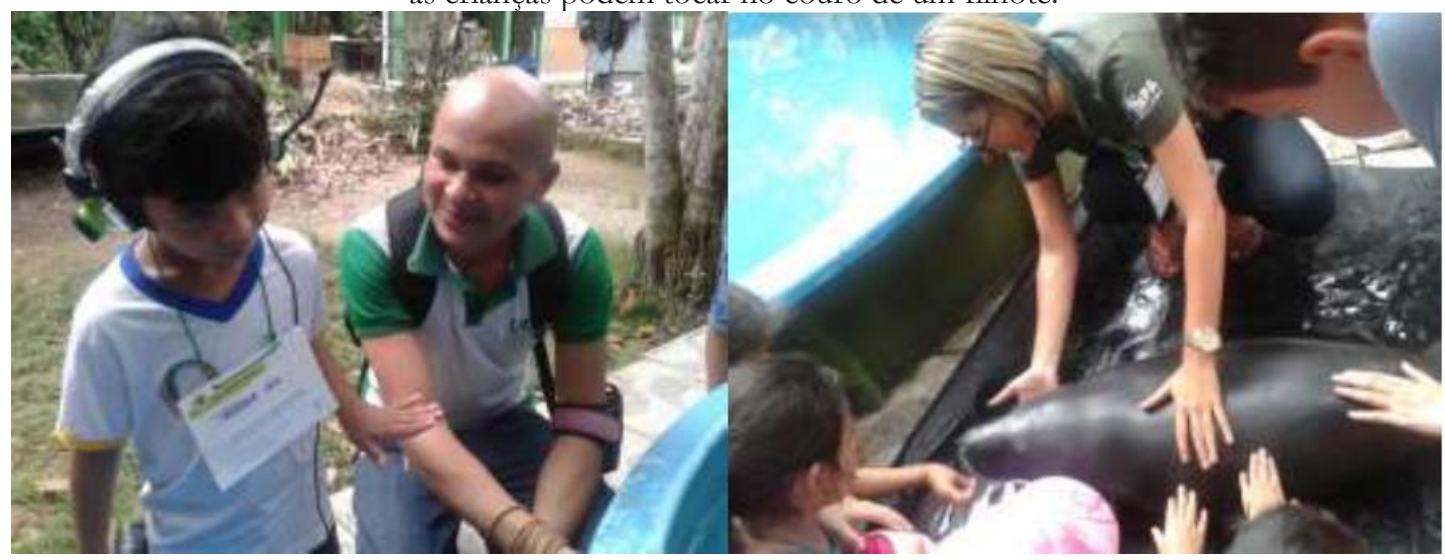

Fonte: Alencar, Fachín-Terán e Barbosa (2016).

Segundo Seiffert-Santos e Cunha (2020), houve três projetos de divulgação científica cultural promovidos junto ao Bosque: a) Projeto Pequenos Guias - que funcionou entre 1995 e 2010, com atividades de crianças locais para uma formação ambiental e que contribuíam como guias no parque para os turistas e visitantes; b) INPA de Portas abertas - projeto no qual os laboratórios do INPA fazem atividade de divulgação sobre suas pesquisas para o público em geral (hoje, foi em parte substituído pela Semana de Ciência e Tecnologia); c) Projeto Circuito da Ciência - escolas são cadastradas e visitam o parque com a presença de vários grupos de pesquisa do INPA e de parceiros que apresentam resultados e produtos das investigações feitas por esses grupos aos escolares.

Este último projeto no campo da divulgação científica e da educação ambiental (o Circuito da Ciência), dirigido pela COEXT (Coordenação de Extensão), está ativo até o presente. Segundo Moreno (2009), estima-se que esse projeto tenha contribuído com atividades de disseminação científica e ambiental para mais de 25 mil estudantes, entre 1999 e 2010. Em folhetos publicados pela COEXT (2012), é possível observar que as atividades se baseiam em três eixos?

\footnotetext{
${ }^{8}$ Disponível em: http://bosque.inpa.gov.br/bosque/index.php/obj.

${ }^{9} \mathrm{Não}$ foram localizadas no site institucional informações relativas aos projetos coordenados pela COEXT e CAAV, somente a sua menção. Também não foi possível ter acesso ao projeto escrito. Assim, a fonte de informação foram os folhetos publicitários do INPA.
} 
- Saúde - doenças tropicais: malária, dengue, leishmaniose; plantas medicinais da Amazônia; e saúde bucal;

- Práticas ambientais - perguntas (Quĩ) aos estudantes sobre redução de emissões de Gases de Efeito Estufa (GEE); produção de mudas; como evitar queimadas urbanas; e os escoteiros do Amazonas;

- Biodiversidade - quelônios da Amazônia; invertebrados terrestres vivos; insetos aquáticos; e mamíferos aquáticos (peixe-boi).

As atividades ocorreram até o ano de 2012 no Bosque da Ciência e Jardim Botânico Adolpho Ducke $^{10}$, envolvendo 45 mil pessoas, entre crianças, jovens e adultos, e com a participação de 182 comunidades urbanas e mais de 520 escolas.

O projeto, que envolve aproximadamente 300 estudantes a cada edição, tem um formato que lembra uma Feira Científica, ou Workshop, com apresentações diversas, tendas, banners, modelos, material biológico conservado etc., dependendo do tipo de exposição que os colaboradores da COEXT entendem adequada para apresentar às escolas visitantes. O Circuito da Ciência tem dez edições anuais, sempre na última sexta-feira do mês (ver Figuras 3 e 4). O Circuito conta com diversas barracas de exposições (que variam entre 15 e 30), também chamadas de estações de visitas, organizadas pelos colaboradores do Circuito da Ciência: grupos de pesquisa do INPA, universidades, entre outras instituições.

Figura 3 - Circuito da Ciência, com participação dos pesquisadores de insetos aquáticos.

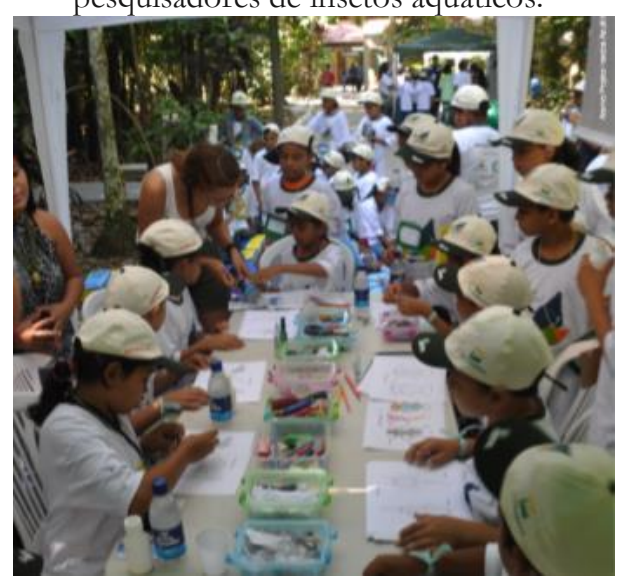

Fonte: Barcellar (2011).
Figura 4 - Edição do Circuito da Ciência de Novembro/2018. Consumo da água.

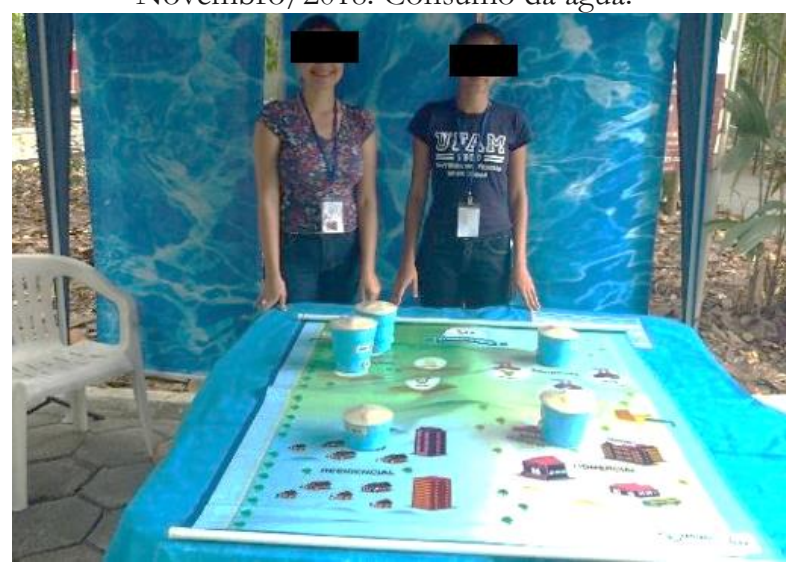

Fonte: Seiffert-Santos (2020a).

Os colaboradores alternam-se a cada edição, o que permite variações ou mesmo diferenças a cada exposição. Além disso, essa estratégia de DC colabora com a participação/diálogo dos professores escolares nas atividades do Circuito da Ciência (MARTINS et al., 2015). Essa diversidade pode ser reportada pelo relato de pesquisas sobre duas edições do Circuito da Ciência, realizadas em 2014, a exemplo de Silva et al. (2015) e de Mota, Fachín-Terán e Gonzaga (2015).

A partir desses dados e considerando-se o arcabouço teórico deste artigo, espera-se ter deixado compreensíveis as possíveis relações entre o ECT, na função de DC, e parte dos processos de comunicação do Bosque da Ciência.

$\mathrm{Na}$ Figura 5, é possível observar um esquema de distribuição das estações de visita com os seus atrativos e seus nomes atuais escritos em português e inglês.

Figura 5 - Esquema dos locais de visitação pública do Bosque da Ciência constantes do folheto destinado ao visitante.

\footnotetext{
${ }^{10}$ Em decorrência das invasões e desmatamentos na área da Reserva Adolpho Ducke, foi criado o Jardim Botânico Adolpho Ducke, em 2000, administrado pela Prefeitura Municipal de Manaus até 2009, quando foi transferida a administração para a empresa privada Musa (BARROSO; MESQUITA, 2014). 


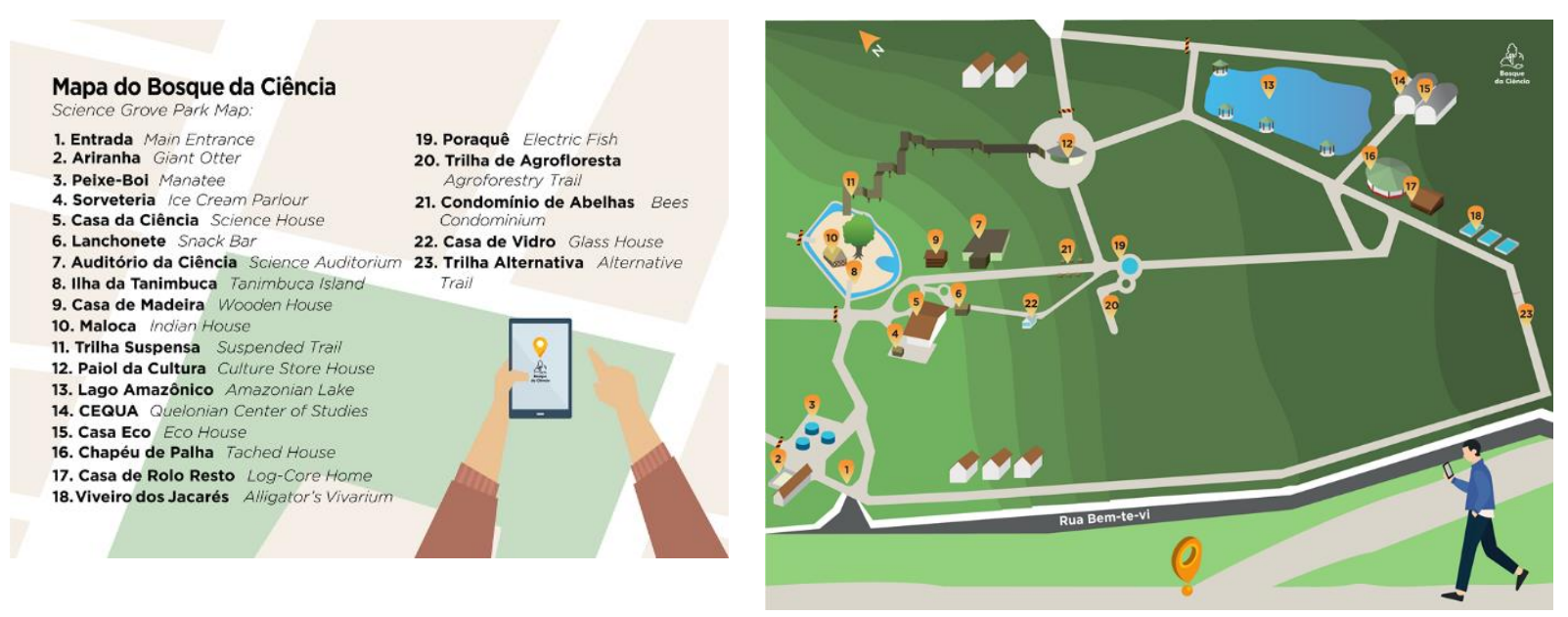

Fonte: COEXT (2018).

\section{PROCEDIMENTOS METODOLÓGICOS}

A pesquisa é de vertente qualitativa com a função de compreensão dos fenômenos humanos e sociais (MALHEIROS, 2011). Segundo Richardson (2012), a investigação qualitativa é a mais adequada para os fenômenos sociais no que se refere aos aspectos metodológicos, às formas de coleta e à análise de dados. Assim, esta é uma pesquisa qualitativa, descritiva e exploratória.

Nesta investigação, construiu-se um corpus de documentos a partir da solicitação feita aos servidores administrativos lotados no Bosque da Ciência, em Manaus (AM), subordinado à Coordenação de Apoio às Áreas de Visitação (CAAV) da Coordenação de Extensão (COEXT) do Instituto Nacional de Pesquisa da Amazônia (INPA).

O critério de escolha do ECT deu-se por meio da seleção de instituições de pesquisa que realizam DC com apresentação de ECT na cidade onde o pesquisador reside - a saber, Manaus (AM). No caso, havia apenas o Museu da Amazônia (ONG Musa), o Museu Amazônico (administrado pela Universidade Federal do Amazonas) e o Bosque da Ciência/INPA. Foi selecionado este último devido à sua presença no catálogo da ABCMC (2015).

Nesta investigação, foi adotada uma análise categorial simples para os termos inicialmente formulados por Bardin (2009) e por Richardson (2012). A pesquisa deu-se a partir dos documentos recolhidos: planos de trabalhos dos servidores; planos de trabalho dos monitores; planilha eletrônica das solicitações de agendamento de visitas via internet do período de junho de 2016 a dezembro de 2018; relatório de gestão; site do Bosque; panfletos de divulgação do Bosque; registro fotográfico das estações de visita pelo pesquisador. Os dados de agendamento de visita presentes na planilha, após serem reorganizados, foram tabulados. A partir da tabulação, utilizou-se de um tratamento de análise descritiva de conteúdo categorial (BARDIN, 2009), construindo-se um gráfico de frequência de visitação a partir das variáveis já explicitadas no próprio documento.

Segundo Bardin, a análise de conteúdo pode ser definida como

Um conjunto de técnicas de análise das comunicações visando obter, por procedimentos sistemáticos e objetivos de descrição do conteúdo das mensagens, indicadores (quantitativos ou não) que permitam a inferência de conhecimentos relativos às condições de produção/recepção (variáveis inferidas) destas mensagens. (BARDIN, 2009, p. 44).

Foram realizadas algumas visitas ao parque, bem como conversas com servidores e monitores sobre o funcionamento das atividades e registro no diário de campo.

Dentre as variáveis constantes na planilha eletrônica de agendamento de visitas que foi disponibilizada, destacam-se as seguintes: nome da instituição solicitante; natureza jurídica, pública ou privada; nível de escolaridade do grupo de visitação; característica do grupo escolar; informações adicionais; presença de portador de necessidades especiais; ano escolar; turno da visita; data; quantidade de alunos pretendidos; quantidade de alunos presentes; quantidade de outros/acompanhantes pretendidos; quantidade de outros/acompanhantes presentes; primeira visita; como foi informado sobre o Bosque da Ciência; pontos de visitação pretendidos; decisão do moderador; e idade do grupo. 
De forma a propiciar uma análise qualitativa categorial, procedeu-se a uma reorganização das variáveis da planilha. As variáveis das solicitações que estavam com campos vazios acima de 70\% dos registros (ano escolar, quantidade de alunos presentes, quantidade de outros/acompanhantes presentes e idade do grupo), por exemplo, deixaram de ser incluídas na análise categorial.

Os dados estão apresentados em: as atividades das equipes de colaboradores, servidores e monitores do Bosque da Ciência, e os dados das solicitações de visita.

A investigação orienta-se através das seguintes questões: a) Quais são as funções e as atividades da equipe de trabalho do Bosque da Ciência com relação à atividade de popularização da Ciência e Tecnologia?; b) Quais são os perfis dos visitantes que encaminham a solicitação de visita e os seus interesses pelo ECT?; e c) Como essa dinâmica dos servidores e das solicitações de visita apresentam o perfil e os interesses dos visitantes de origem escolar (educação formal)?

\section{RESULTADOS E DISCUSSÃO}

\section{Equipe de Trabalho}

O Bosque da Ciência é administrado pela Coordenação de Apoio às Áreas de Visitação (CAAV), que conta com seis técnicos administrativos, cujas funções estão em consonância com os objetivos e as metas do plano individual de trabalho, no qual estão discriminados o planejamento, o treinamento e a execução do Projeto Circuito da Ciência e Estágio Curricular por monitoria, bilheteria, apoio e supervisão das visitações. Entre os técnicos da equipe de trabalho, há pessoas com formação em Pedagogia, Assistência Social, Agronomia e Engenharia Florestal.

A coordenação do CAAV tem a função de supervisionar e apoiar os trabalhos de recepção de visitantes, zelar pela manutenção do parque e realizar o planejamento e a execução da sua coordenação. Não há necessariamente atividade de produção intelectual, pois todos são técnicos, tendo como função apoiar os pesquisadores e as atividades dos laboratórios.

Os objetivos do CAAV são: organização, realização e apoio a eventos científicos, educacionais e culturais na área da visitação; recepção, supervisão e apoio a grupos de visitantes na área de visitação; capacitação de novos profissionais para as atividades voltadas à área do turismo ambiental, gestão administrativa e manejo ambiental com ênfase no bioma amazônico; e promoção e difusão científica e educação ambiental no INPA (INPA, 2018a, Plano de Trabalho dos Servidores - Metas Individuais).

Integrantes do grupo de trabalho e treinamento, os monitores de recepção turística são os que fazem os percursos nas estações de visita. Identificaram-se 13 monitores durante o período de busca de dados, dos quais 4 estagiavam no período vespertino, e 9 aos sábados e domingos. Esses monitores eram estudantes do curso de Turismo nas seguintes instituições: Centro Universitário Fametro, Universidade do Estado do Amazonas e Universidade Nilton Lins.

Os estagiários de recepção têm os seguintes objetivos: mediar ações de recepção junto ao público que visita o Bosque da Ciência e contribuir para o desenvolvimento de ações educativas no contexto do Bosque da Ciência. Destacam-se como objetivos específicos: acompanhar os visitantes e as escolas pelas trilhas e fornecer informações simples sobre os centros de visitacõos e sobre a flora e a fauna, tentando despertar no visitante o interesse maior pela paisagem natural do local; participar dos projetos desenvolvidos no Bosque da Ciência, como o Circuito da Ciência e as atividades organizadas em datas comemorativas (Semana do Meio Ambiente, por exemplo). Os estagiários elaboram um plano individual de estágio contemplando a formação preparatória, a leitura bibliográfica, o auxílio em oficinas, o acompanhamento em visitação, o atendimento na Casa da Ciência e a entrega do relatório final pessoal (INPA, 2018b, Plano de Trabalho dos Estagiários - Metas Individuais, grifo nosso).

Os monitores de manejo florestal e paisagismo também eram 13, dentre os quais 8 estagiavam no turno da manhã e 5 no turno vespertino, nos dias úteis. Os estagiários eram estudantes dos seguintes cursos: técnico em Meio Ambiente pelo Centro de Educação Tecnológica do Amazonas (CETAM) e Centro de Ensino Técnico (CENTEC); graduação em Biologia pela Universidade Estácio de Sá; graduação em Engenharia Ambiental pela Universidade Nilton Lins; e graduação em Gestão Ambiental pelo Instituto de Ensino Superior - UNIASSELVI. 
Os objetivos dos estagiários de manejo florestal e paisagismo são: capacitar novos profissionais para atividades voltadas para a área ambiental, com ênfase no bioma amazônico, com o intuito de torná-los mais preparados tecnicamente, de modo a responderem às solicitações do cotidiano do Bosque da Ciência, tanto em relação aos assuntos socioambientais quanto às questões pedagógicas e de linguagem científica. Os seus objetivos específicos são: acompanhar a demonstração de atividades rotineiras na produção de mudas de espécies florestais e agronômicas no Viveiro do Bosque da Ciência; acompanhar e realizar práticas silviculturais adotadas na área florestal; orientar visitantes do Bosque da Ciência quanto aos assuntos da área técnica, da educacional e do receptivo (INPA, 2018b, grifo nosso).

No cronograma de trabalho, estão as atividades de coleta de sementes, apoio às oficinas, participação em atividades ambientais, cuidado com o paisagismo do parque, plantio de mudas, produção de mudas, realização de visitas guiadas e entrega do relatório final (INPA, 2018b, grifo nosso).

Observou-se que todos os estagiários eram responsáveis por visitas guiadas e participavam das atividades pedagógicas ambientais. Contudo, um grupo tinha como foco o manejo florestal e o paisagismo, e o outro, a recepção de visitantes e o estudo programado.

Sobre a formação dos monitores, não foi entregue documento escrito. Todavia, em trabalho publicado pelo INPA (HIGUCHI; FARIA, 2002) e, depois, em conversa registrada no diário de campo com os monitores e servidores do Bosque da Ciência, tomou-se conhecimento de que, após o processo seletivo semestral, na primeira semana de estágio, eles participam de um evento de capacitação com palestras, atividades de reconhecimento das estações de visitas e dos laboratórios e integração com os servidores e outros monitores. Destacam-se, dentre as informações, as das palestras de cada laboratório com espaço no Parque, a exemplo do Laboratório de Mamíferos Aquáticos (LMA), do Grupo de Pesquisa com Abelhas (GPA), do Centro de Pesquisa de Quelônios da Amazônia (CEQUA), do Laboratório de Psicologia e Educação Ambiental (LAPSEA), do Herbário e do grupo de pesquisa que estuda o poraquê. $\mathrm{Na}$ atividade de reconhecimento das espécies de plantas amazônicas, houve a participação de agrônomo e/ou engenheiro florestal; e, na de reconhecimento das estações de visita, o próprio coordenador da CAAV esteve presente. Foi mencionado o recebimento de material de leitura abordando as atividades de recepção e também o atendimento ao público visitante.

Nesta pesquisa, é possível elencar um programa de formação de monitores e professores usuários do Bosque ${ }^{11}$ para o desenvolvimento de experiências positivas de educação. Todavia, para mais fatores a serem pensados como programa de formação de monitores, pode-se consultar HooperGreenhill (1999), Falk e Storksdieck (2005), Rodari e Merzagora (2007), Marandino (2008), National Research Council (2009), Queiroz et al. (2011), Bizerra e Marandino (2014), e Carvalho e Pacca (2015), entre outros.

Entende-se que há repetição de alguns problemas já encontrados em outras pesquisas sobre o projeto de monitoria em espaços não formais, aqui, em parque temático, quais sejam: reduzido quadro de monitores em vista da numerosa visitação (veja-se na próxima seção); estágio voluntário sem repasse de valores de transporte, alimentação e custeio de material de leitura; formação e maturação da experiência de monitoria curta (seis meses); grande rotatividade de monitores; desligamento sem incentivo de permanência e integração com outros setores da instituição, ao término do estágio monitorial.

Essas circunstâncias podem ser balanceadas com medidas possíveis, como, por exemplo:

- Realização de convênio com instituições de ensino superior e órgãos ligados à profissionalização de esfera municipal ou estadual; efetivação de programa de formação de visita guiada a professores da educação básica e em temáticas específicas (KATZ et al., 2011); e elaboração de sequências didáticas (PASCUAL; ARANZABAL, 2014) - com isso, fazer o banco de voluntários docentes do Bosque;

\footnotetext{
11 Azevedo, Higuchi e Barcelos (2009) informam que o LAPSEA/INPA possui um projeto de formação continuada de professores da rede básica sobre o conhecimento científico e cotidiano e a floresta Amazônica numa perspectiva socioambiental.
} 
- Estabelecimento de convênios com órgãos de profissionalização da esfera estadual, municipal e federal, com disponibilidade para bolsas, ou a constituição de fundação para captação de recursos ${ }^{12}$;

- Desenvolvimento de programas de formação de monitores em que haja integração com os laboratórios para possibilitar outros estágios na área da pesquisa e para os quais se mantenham alguns dias do mês contribuindo para a formação de novos monitores (LUEHMANN, 2009);

- Planificação de atividades de registro da memória do Bosque, reuniões de formação e decisões e redações/dissertações temáticas sobre a realidade do Bosque para o banco de experiências e boas práticas (BASSOLI, 2013);

- Realização anual de um encontro dos monitores do Bosque da Ciência para compartilhar experiências, projetos e construção de network junto à administração do Bosque (HIGUCHI; FARIAS, 2002).

\section{Solicitação de Visita}

Em relação às solicitações, foram identificados 1.958 pedidos de agendamento de visita ( $n=1.958)$, entre junho de 2016 e dezembro de 2018, sendo que 914 foram de escolas públicas ( $n=914$ grupos de escolas; 46,6\%); 611 de escolas privadas ( $\mathrm{n}=611$ grupos de escolas; $31,2 \%$ ); e 433 de outras instituições ( $\mathrm{n}=433$ grupos; $22,1 \%$ ). Destas últimas, destacam-se igrejas ( $\mathrm{n}=53$ grupos), escoteiros ( $\mathrm{n}=46$ grupos) e centros de atenção social ou filantrópicos ( $\mathrm{n}=20$ grupos), entre outros.

Nesse período, foram registrados em média 63,1 grupos/mês, 3.700 visitantes/mês e 58,1 visitantes/grupo/mês, o que equivale a uma média de 142 pessoas por dia (considerando a semana de visitação de seis dias).

Pode-se destacar que os níveis de escolaridade dos grupos de estudantes em visita foram: infantil ( $\mathrm{n}=272$ grupos; 13,9\%); fundamental ( $\mathrm{n}=440$ grupos; $22,5 \%$ ); médio ( $\mathrm{n}=121$ grupos; $6,2 \%$ ); e superior ( $\mathrm{n}=125$ grupos; $6,4 \%$ ). As outras instituições apresentaram grupos mistos com visitantes nos níveis de escolarização infantil, fundamental, médio e superior ( $\mathrm{n}=458$ grupos; $23,4 \%$ ). O grupo majoritário de visitas agendadas foi o dos escolares dos níveis infantil e fundamental, somando 36,4\% das solicitações.

As visitas pelo turno matutino foram mais solicitadas $(n=1.298 ; 66,3 \%)$ do que as do vespertino $(n=658 ; 33,6 \%)$. Podem-se associar as visitas matutinas às de escolas do nível infantil e anos iniciais do ensino fundamental, considerando ser esse o horário em que normalmente funcionam tais escolas. Em termos anuais, essas solicitações de visitas foram assim distribuídas: 2016 ( $\mathrm{n}=481$ grupos; 24,6\%); 2017 ( $n=775$ grupos; 39,6\%); e 2018 ( $n=697$ grupos; 35,6\%). Dessas solicitações, somente 8,58\% $(\mathrm{n}=168)$ declararam a presença de pessoas portadoras de necessidades especiais.

Nesses interstícios, os meses mais visitados foram: junho, em decorrência da Semana do Meio Ambiente; e outubro, por conta da Semana de Ciência e Tecnologia, do período comemorativo das crianças e do aniversário do INPA (Figura 6). As datas comemorativas escolares têm uma forte influência nas visitas ao Bosque. Os meses de dezembro, janeiro e julho são menos visitados, em associação ao recesso escolar; nos meses de fevereiro e março, as visitas se iniciam com o retorno escolar.

Figura 6 - Distribuição do número de visitantes no Bosque da Ciência a partir das solicitações formais de visita (2016 a 2018).

\footnotetext{
12 A Prefeitura Municipal de Manaus, no ano de 2019, realizou um convênio com a COEXT/INPA para manter com bolsas municipais os monitores depois do aviso de fechamento de visitas monitoradas e da redução do quadro de servidores lotados neste setor. É dessa forma que se tem mantido o funcionamento do Bosque da Ciência até o presente.

Educação em Revista| Belo Horizonte|v.38|e29448|2022
} 


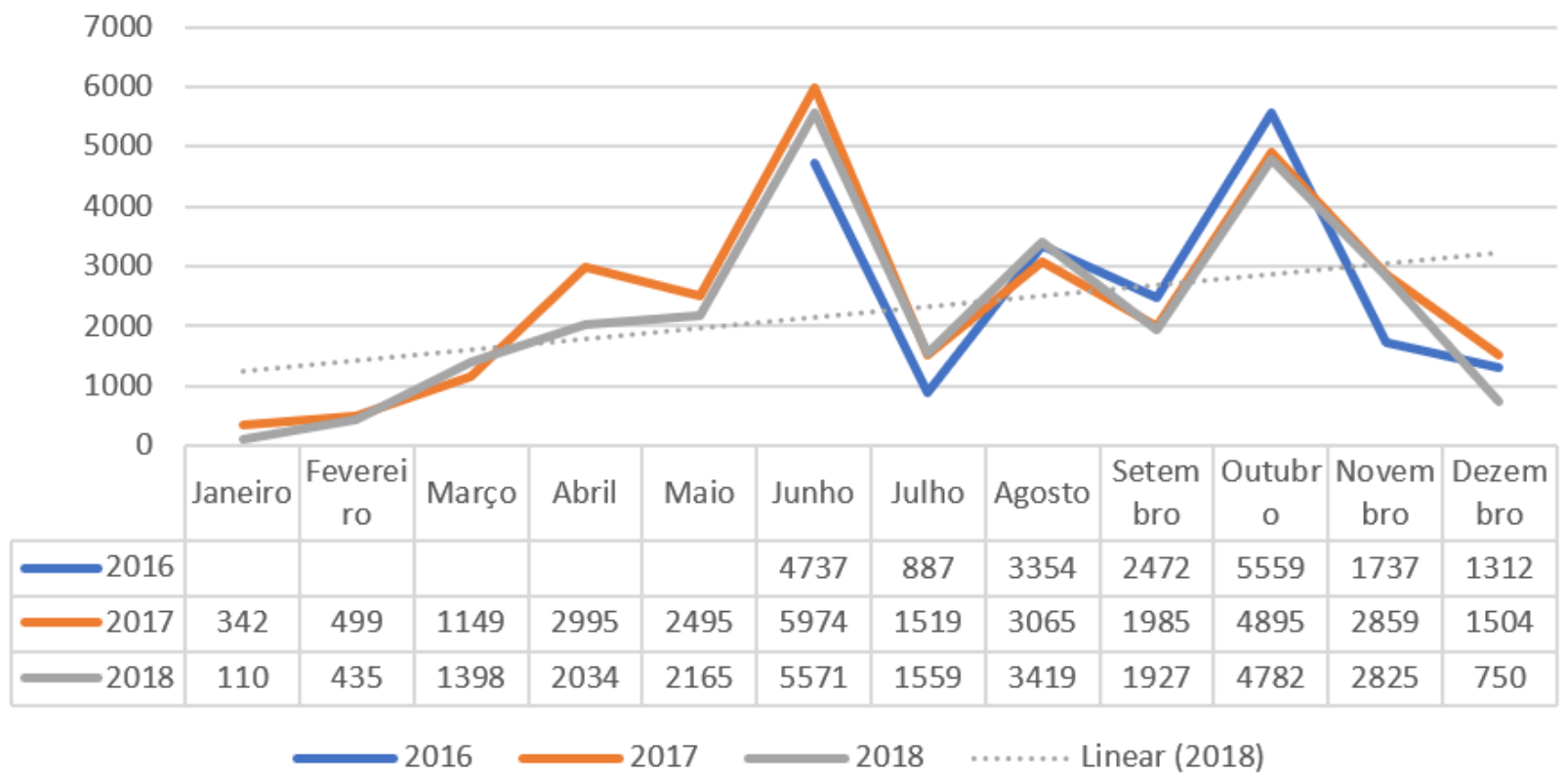

Fonte: Dados reconstruídos pelo pesquisador.

Nesse período de três anos, o Bosque recebeu 95.356 visitantes (n=95.356), uma média de 48,7 visitantes por solicitação. Contudo, deve-se salientar que as solicitações formais são uma parte da demanda que o Parque recebe, não contemplando as entradas gratuitas para visitantes com idade inferior a 10 anos ou maiores de 60 anos, os pagantes de visita espontânea (individuais, grupos e famílias) e também os grupos não agendados (esses dados possuem registro físico). Também não são contemplados os visitantes dos dias em que a entrada é franca, sem contagem na bilheteria, a exemplo da semana do aniversário do Bosque da Ciência (primeira semana de abril), a semana de aniversário do INPA, a Semana do Meio Ambiente e a Semana de Ciência e Tecnologia.

A frequência dos visitantes, ilustrada na figura anterior, é proporcional à frequência dos acompanhantes responsáveis pelos grupos de visitantes (Figura 7).

Figura 7 - Distribuição do número de acompanhantes aos grupos de visitas no Bosque da Ciência a partir das solicitações formais de visita (2016 a 2018).

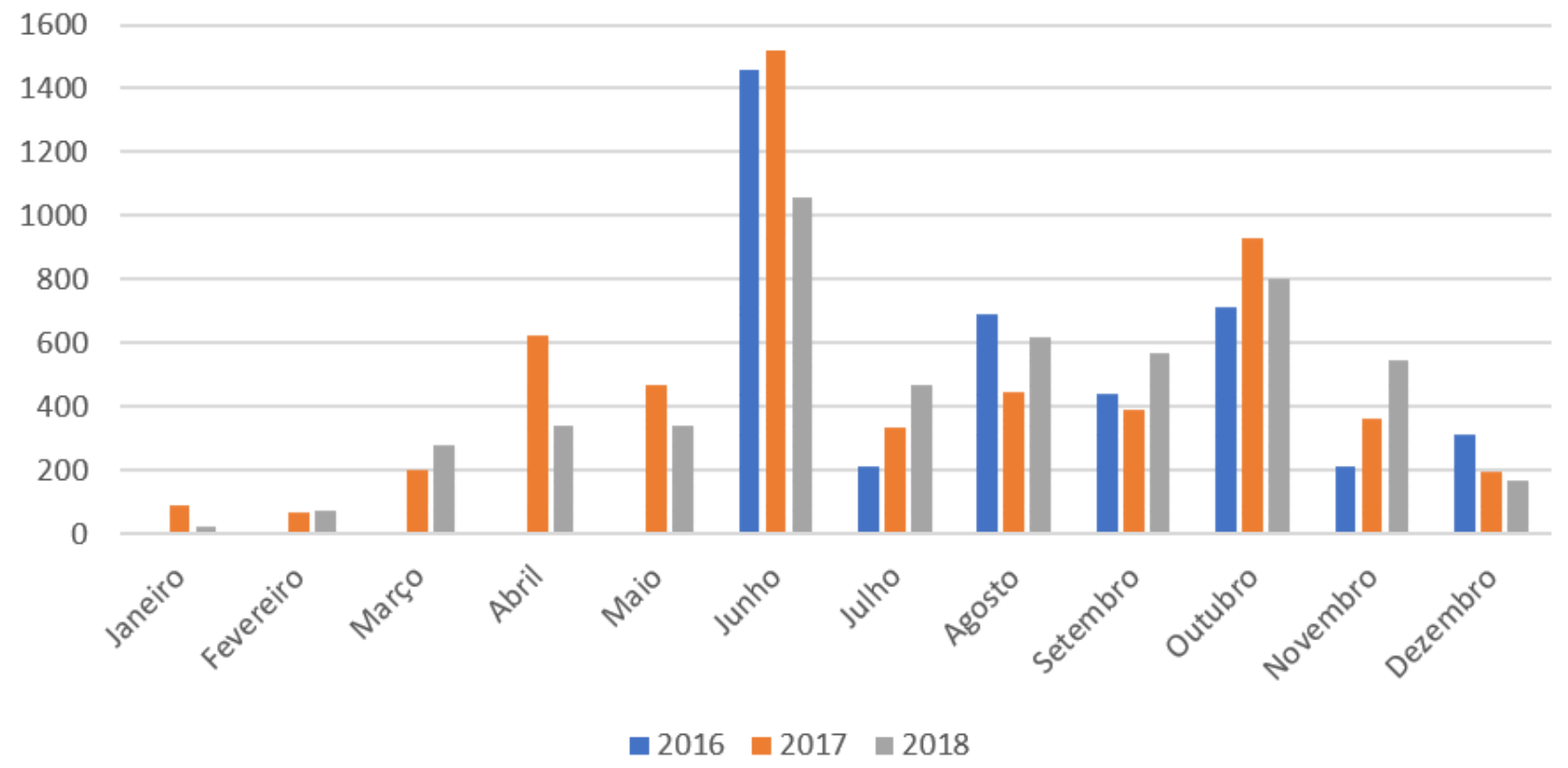

Fonte: Dados reconstruídos pelo pesquisador. 
As visitas são realizadas em grupos, limitadas a cem pessoas por grupo e 300 pessoas por turno. Assim, realizou-se a contagem das solicitações em grupos de múltiplos de 50, ou seja, 50 visitantes (Quadro 1).

Quadro 1 - Distribuição em grupos múltiplos de 50 visitantes (2016 a 2018).

\begin{tabular}{|l|c|c|c|c|c|c|c|c|}
\hline Grupos & $\mathbf{5 0}$ & $\mathbf{1 0 0}$ & $\mathbf{1 5 0}$ & $\mathbf{2 0 0}$ & $\mathbf{2 5 0}$ & $\mathbf{3 0 0}$ & $\begin{array}{c}\text { Maior de } \\
\mathbf{3 0 0}\end{array}$ & $\begin{array}{c}\text { Não } \\
\text { informado }\end{array}$ \\
\hline Visitantes & 1.389 & 440 & 75 & 27 & 8 & 2 & 11 & 6 \\
\hline Percentual & $70,94 \%$ & $22,47 \%$ & $3,83 \%$ & $1,38 \%$ & $0,41 \%$ & $0,10 \%$ & $0,56 \%$ & $0,31 \%$ \\
\hline
\end{tabular}

Fonte: Dados reconstruídos pelo pesquisador.

Mais de 70\% das solicitações envolveram grupos de até 50 pessoas, no período informado. Percentual semelhante foi observado em relação ao número de acompanhantes e responsáveis; os grupos com até cinco pessoas adultas representaram 47,75\% (n=935). Veja-se o Quadro 2.

Quadro 2 - Distribuição de acompanhantes/responsáveis por grupos de visitantes (2016 a 2018).

\begin{tabular}{|l|c|c|c|c|c|c|}
\hline $\begin{array}{l}\text { Acompanhantes } \\
\text { por Grupos }\end{array}$ & $\mathbf{5}$ & $\mathbf{1 0}$ & $\mathbf{1 5}$ & $\mathbf{2 0}$ & Maior de 20 & Não informado \\
\hline $\begin{array}{l}\text { Acompanhantes/ } \\
\text { responsáveis }\end{array}$ & 935 & 557 & 209 & 110 & 125 & 22 \\
\hline Percentual & $47,75 \%$ & $28,45 \%$ & $10,67 \%$ & $5,62 \%$ & $6,38 \%$ & $1,12 \%$ \\
\hline
\end{tabular}

Fonte: Dados reconstruídos pelo pesquisador.

Ressalta-se que, no período de análise, a maioria dos visitantes assinalou que estava visitando o Bosque da Ciência pela primeira vez $(n=1.196 ; 61 \%)$, e, portanto, somente 37,8\% $(n=740)$ já o tinham visitado.

Embora o normal seja que as solicitações sejam autorizadas, há registro de pedidos negados pelo moderador ( $n=281 ; 14,3 \%$ ) em decorrência de remarcação de visitas e outras causas.

Uma informação interessante refere-se à fonte que sugeriu a atividade no Bosque da Ciência, ou seja, como o visitante ficou sabendo sobre a possibilidade de realizar visitas em grupos. O comum é que o "boca a boca" seja a principal forma de divulgação (COSTA; IMHOFF; BORGES, 2015); mas, em relação ao Parque, as fontes foram sites da Internet com 33,25\% $(\mathrm{n}=651)$, as redes sociais $(10,9 \%$, $\mathrm{n}=213)$, os jornais $(6,8 \%, \mathrm{n}=133)$ e outros $(0,4 \%, \mathrm{n}=9)$. A maioria informou ter tido conhecimento das visitas ao Parque por várias fontes, o que chamamos de fonte mista, com 39,6\% ( $n=775)$, opção que abrange as indicações de familiares, amigos e colegas de trabalho.

Os objetivos e/ou motivações para as visitas de público proveniente dos níveis fundamental, médio e superior estão circunscritos a quatro grupos: a) conhecimentos escolares, ou seja, atividades que geram relatórios técnicos, ou algum tipo de atividade análoga à avaliação escolar; b) experiência de enriquecimento sobre o Bosque da Ciência, relacionada à biodiversidade e ao meio ambiente; c) atividade de evento, premiação escolar ou projetos; d) outros, como remarcação de atividade, ou reconhecimento do INPA. Isso pode ser visto no Quadro $3^{13}(22,1 \%$ das solicitações; $n=433)$.

Quadro 3 - Motivações para as visitas (2016 a 2018).

\footnotetext{
${ }^{13}$ Esse quadro apresenta totais diferentes dos elencados no Quadro 6, tendo em vista que foram desconsideradas as solicitações que não preencheram essa informação e também as relativas aos grupos mistos, que são heterogêneos, não escolares, cujas visitas não têm, necessariamente, intenção educativa científica ou ambiental.

Educação em Revista|Belo Horizonte|v.38|e29448|2022
} 


\begin{tabular}{|l|c|c|c|}
\hline Motivações & Fundamental & Médio & Superior \\
\hline Experiência de enriquecimento & $175(58,5 \%)$ & $44(61,1 \%)$ & $15(24,2 \%)$ \\
\hline Atividade de evento & $76(25,4 \%)$ & $4(5,5 \%)$ & $14(22,6 \%)$ \\
\hline Conhecimento escolar & $37(12,4 \%)$ & $21(29,1 \%)$ & $31(50 \%)$ \\
\hline Outros & $11(3,7 \%)$ & $3(4,1 \%)$ & $2(3,2 \%)$ \\
\hline Soma por nível & 299 & 72 & 62 \\
\hline
\end{tabular}

Fonte: Dados reconstruídos pelo pesquisador.

Observa-se, no Quadro 3, que as principais motivações dos níveis fundamental e médio são semelhantes. Há uma ênfase na experiência de enriquecimento na maior parte das solicitações, superando os $50 \%$. Todavia, as atividades de eventos ocorrem em percentual significativo no nível fundamental, em especial em decorrência de premiação e de alguns projetos em nível escolar, ou em comemoração de datas especiais. Por sua vez, a ênfase no nível médio refere-se às atividades de conhecimento escolar, em especial em visitas técnicas de cursos técnicos e aulas ligadas à Biologia e à Educação Ambiental. Já no nível superior, a ênfase das visitas dá-se no conhecimento escolar, ou seja, atividades de aulas práticas de disciplinas e outras atividades semelhantes, para experiência de enriquecimento, além de atividades de eventos programados. Podem-se relacionar esses resultados com os obtidos por Seiffert-Santos e Cunha (2019) em estudo envolvendo pesquisas sobre educação científica em espaços não formais, nos trabalhos apresentados no Encontro Nacional de Pesquisa em Educação em Ciências (ENPEC), entre 2011 e 2017, relativas às três categorias desta pesquisa, a saber: de enriquecimento cultural (similar à experiência de enriquecimento), de complementação escolar (similar a conhecimento escolar) e de alternativas não formais. No trabalho citado, a maior frequência de trabalhos foi encontrada na categoria de enriquecimento cultural, semelhante a este estudo.

Os objetivos e as motivações das atividades no nível infantil são mais homogêneos. As visitas são para a aula passeio, socialização, premiação por visita ao bosque, experiência com a fauna e a flora, comemoração do Dia da Criança e do Meio Ambiente.

Observa-se, a partir dos dados apresentados anteriormente, que a maioria das visitas ao Bosque da Ciência se dá pela manhã, por escolas públicas, por estudantes do nivel infantil e fundamental, com grupos de até 50 pessoas, e com o acompanhamento de grupos de cinco pessoas responsáveis com objetivos/motivações de experienciar os ambientes, a biodiversidade e a socialização, especialmente na Semana do Meio Ambiente e na Semana da Ciência e Tecnologia.

A única pesquisa localizada que apresenta dados relativos à visitação do Bosque da Ciência é a de Maciel e Fachín-Terán (2014), abrangendo o período de 2010 a 2012, com números considerados elevados se comparados aos obtidos pela presente pesquisa: mais de 100 mil visitantes por ano, e com média superior a 600 escolas por ano. Contudo, reforça-se a observação de que, nos dados aqui presentes, não foram incluídos os registros físicos não digitalizados.

Retomando as motivações de visitas escolares, nota-se o uso frequente de palavras como experiências, sensibilizar e conhecimento, entre outras com o sentido semelhante, na categoria de experiência de enriquecimento, na qual se percebe uma crença de que a experiência gera o conhecimento acerca do meio ambiente, da fauna e da flora, sem que haja o peso das obrigações escolares. Por outro lado, identifica-se que a categoria conhecimentos escolares tem como sentido o de aula prática, a elaboração de relatórios e o estabelecimento de relações entre a teoria e o mundo prático na natureza: um entendimento de que os conceitos vistos em aula, na escola, podem ser observados no espaço não formal, como se ocorresse uma confirmação. Nesse sentido, é possível inferir que alguns conceitos envolvendo relações ecológicas, algumas estruturas morfológicas e a análise de alguma situação ambiental, especialmente associada à destruição de origem antrópica ao meio ambiente, possam ser apreendidos sem muitas dificuldades no ECT, na condição de fragmento florestal. Contudo, é necessário planejar, fazer acertos prévios junto ao grupo e preparar o local de forma a apreender o conceito na observação. É importante ressaltar que se trata de uma situação construída, uma observação dirigida e não uma observação natural pura ou espontânea. É fundamental haver a reflexão epistemológica para não se permear um empirismo ingênuo, bem como visualizar o fragmento florestal, nesse caso de mata secundária, como ambiente puro, não obstante seja uma área que propicie atividade com o meio florestal 
amazônico, mas modificado, e com muitos vegetais plantados em regime de manejo florestal e paisagismo.

\section{Dados de solicitações de visitas às estações}

Levando-se em conta que são 20 as estações e estimando-se a permanência mínima de dez minutos em cada uma delas, a visitação duraria pelo menos três horas, sem se levar em consideração o tempo de caminhada nas trilhas entre uma estação e outra. Dessa forma, é fundamental planejar bem o roteiro de visitação, selecionando as estações e focando em temáticas e possíveis observações, de forma a não deixar os visitantes exaustos pela caminhada nas trilhas florestais, possibilitando que desfrutem das experiências ricas que uma estação tem a oferecer e viabilizando diálogos e interações com professores e monitores.

No formulário eletrônico de agendamento do Bosque da Ciência, são disponibilizadas as seguintes opções de escolha: Caminhada pelas Trilhas; Centro de Quelônios da Amazônia (CEQUA); Sessão do Planetário; Circuito da Ciência; "Nenhum" [destes]; e "Todos" [estes].

Logo abaixo desse item, é solicitado que se informe o objetivo da visita, para que se dê a seleção prévia das estações, a fim de haver um planejamento da recepção dos grupos ao parque e também o controle do número de monitores e as possíveis combinações de estações, para que não haja congestionamento dos espaços.

Ao assinalar a opção "Caminhada pelas Trilhas", é possível fazer combinações envolvendo as seguintes estações: Portaria, Viveiros da Ariranha e dos Peixes-boi, Ilha da Tanimbuca, Trilha Suspensa, Paiol da Cultura (passagem sem entrada), Lago Amazônico (as visitas ao CEQUA e aos viveiros dos jacarés são opcionais) e retorno pela estação desativada das Ilhas das Inajás (devido às rampas de acessos com acessibilidade a cadeirantes), trilha de acesso direto ao ambiente externo da Casa da Ciência, ou trilha que passa pela Casa de Vidro e Lanchonete (chegando ao ambiente externo da Casa da Ciência, cuja visitação se dá quando não esgotado o tempo planejado). Nesse percurso, é possível visitar de 7 a 11 estações.

O CEQUA apresenta duas possibilidades de acesso. Uma delas é realizar a tradicional Caminhada pelas Trilhas, com foco na visita ao CEQUA e aos Viveiros dos jacarés (parte do CEQUA); a outra é pela trilha de acesso ao Recanto das Inajás (grafado por Poraquê nos esquemas de visitações atuais), que dispõe de acessibilidade a cadeirantes, cujo retorno se dá pelo mesmo caminho.

A Sessão do Planetário, que ocorre em uma das salas da Casa da Ciência, não é executada pela equipe do Parque, mas por graduandos ou egressos dos cursos de Ciências Naturais e de Física da Universidade Federal do Amazonas, muitos deles ligados a projetos de extensão da universidade ou de iniciação à docência. Por envolver uso de espaço do INPA por terceiros, o agendamento das visitas ocorre de acordo com a disponibilidade das programações do Parque.

No Projeto Circuito da Ciência, as escolas são convidadas a se cadastrarem para serem agendadas em uma das dez exibições anuais.

A totalidade das opções é apresentada na opção "Todos", tornando possível o agendamento de acordo com as possibilidades das atividades, conforme os objetivos da visita. E a opção "Nenhum" está associada a eventos e atividades próprias de aulas práticas ou visitas técnicas, nas quais não há necessidade de monitor, uma vez que se trata de atividade dirigida por instrutor ou professor vinculado ao grupo de visitantes.

A Figura 8 apresenta a frequência relativa das opções selecionadas. A opção "Nenhum" foi pouco computada ( $n=66)$, e a opção "Todos", a mais selecionada $(n=1.451)$. Todavia, ao se fazer a decomposição das opções, foi percebido que a opção mais selecionada foi "Caminhada pelas Trilhas", o que, de certa forma, confirma a motivação das visitas. Os dados na Figura 8 mostram as motivações relacionadas à experiência de enriquecimento e ao conhecimento escolar (Quadro 3).

Figura 8 - Frequência relativa de solicitações de visitas a partir da escolha das estações de visita do Bosque da Ciência (2016 a 2018). 


\section{Solicitações}

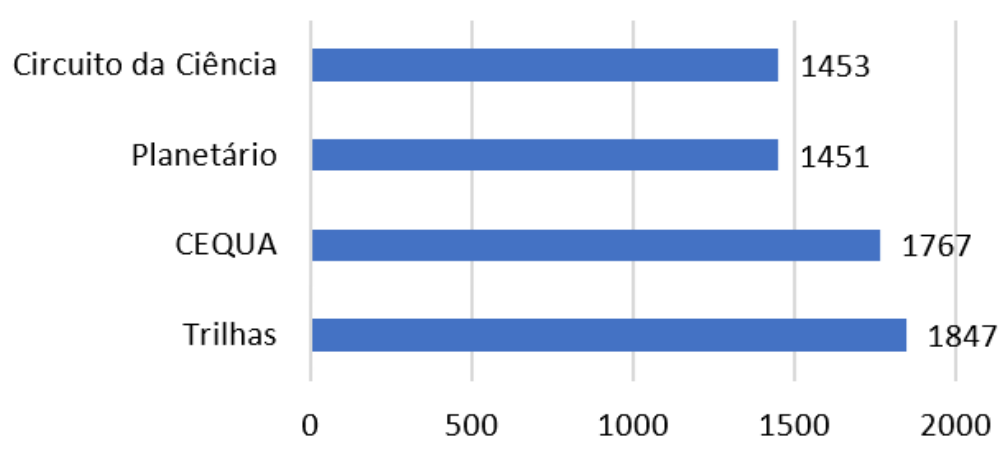

Fonte: Dados reconstruídos pelo pesquisador.

Entretanto, a diferença entre a opção mais assinalada e a menos assinalada é de aproximadamente $21,4 \%$ ( $\mathrm{n}=396)$, confirmando que todas as opções são bem solicitadas. O NRC (2009) sugere percursos de visita, que sejam como narrativas para que cada estação contribua para a construção de sentido ao visitante - ele individualmente ou em grupo, todavia, em ambientes fechados normalmente. Isso é relativamente mais controlável em ambientes planejados e fechados. Porém, conforme já foi dito, os ambientes abertos possuem as limitações de o acervo ser plantado, as edificações serem fixas e sujeitas ao intemperismo, às estações do ano e ao horário do dia. Isso leva a um efeito especial pela vivência dos ritmos naturais, algo que somente o experenciar com todos os sentidos conduz a um saber de contato e que não é reduzido a apenas um saber cognitivo pelo design da exposição.

\section{CONSIDERAÇÕES FINAIS}

As considerações aqui apresentadas ocorrem em função do objetivo da pesquisa em uma síntese dos resultados principais da caracterização de um ECT amazônico e no reforço da associação deste espaço não formal ao conceito de Patrimônio Integral e ao ensino de Ciências. O Bosque da Ciência é uma instituição única por suas características - inicialmente, por ter seu enquadramento como Parque Temático e, por conseguinte, pelo fato de ser análogo ao museu de Ciência por essa razão. Ademais, por um lado, o Bosque da Ciência conduz a um lazer científico e ambiental, o que lhe dá uma identidade própria de Parque Temático para a ludicidade; e, por outro lado, aproxima-se menos da ideia de Centro de Ciências que prima pelo experimento e pela aplicação de conceitos científicos.

A equipe de trabalho ligada à Coordenação de Extensão gerencia o espaço em conjunto com os laboratórios de pesquisa do INPA e realiza a DC com papéis distintos: (i) a CAAV gerencia com os monitores as visitas de recepção e a execução do Projeto Circuito da Ciência; (ii) os laboratórios presentes no parque expõem material informativo, como banner e placas interpretativas de sua área de pesquisa que julgam importante popularizar.

A DC é desenvolvida na temática científica e ambiental. É científica devido à presença de criadouros científicos ${ }^{14}$ com presença de mídias interpretativas com informações ligadas a esses criadouros, como o caso do peixe-boi e dos quelônios do CEQUA. É ambiental devido ao fato de o ambiente aberto ter o apelo natural da imersão florestal e, dessa forma, associar-se à conservação dos espécimes amazônicos. A própria documentação do Bosque assume essa temática e se confirma pela solicitação de visita com motivação de experiência de enriquecimento e pelas escolhas ao realizarem as trilhas.

O público visitante predominante é o escolar, em especial a educação infantil e o ensino fundamental. Mas há a presença de diversos grupos. Dessa forma, o parque assume um papel de não

\footnotetext{
${ }^{14}$ A Instrução Normativa IBAMA n ${ }^{\circ}$ 7/2015, de 30 de abril de 2015, informa no seu Artigo 32: “Os criadouros científicos para fins de conservação e mantenedouros somente poderão ser objeto de visitas monitoradas de caráter técnico, didático ou para atender programas de educação ambiental da rede de ensino formal, e desde que não mantenham espécimes dos grupos elencados no artigo anterior. Parágrafo único. As visitas monitoradas deverão ser objeto de aprovação junto ao órgão ambiental competente mediante apresentação de projeto de visitação, sendo vedada a cobrança de qualquer taxa aos visitantes".
} 
escolarizar o passeio, mas permitir que ele seja plural para grupos diversos. Isso fica evidente devido à missão do parque e suas atividades diversificadas, operacionalizadas pelos monitores de recepção e de paisagismo; e à agenda do Bosque da Ciência com atividades variadas, como foi mostrado, a Semana do Meio Ambiente e a Semana de Ciência e Tecnologia, as quais recebem diversas audiências, sendo a visita estimulada nessas datas, com catraca aberta.

Um ponto importante na comunicação desenvolvida no ECT Bosque da Ciência é reconhecer o objeto de observação, que é a razão da experiência e da atividade, e reconhecê-lo como um patrimônio em CT. Entende-se que o conceito adaptado de patrimônio não deve se limitar à espécie a ser preservada, mas ser estendido à noção de identidade e pertencimento ao universo amazônico, considerando que patrimônio é algo que traz o sentimento de posse, de vínculo a algo a que se pertence: é amazônico, é brasileiro, e é da humanidade, de acordo com a Portaria no 422/2017 MC/IBM, o ICOM e a Constituição Federal do Brasil (BRASIL, 1988). A partir desse conceito, considera-se que o Bosque da Ciência realiza o processo de musealização como patrimônio das riquezas amazônicas, vivas e presentes, numa forma inovadora e distinta em relação aos museus cobertos.

A identidade institucional de parque temático para museu vivo formalmente eleva, a um novo degrau, o conceito organizacional e o diálogo com integração entre os laboratórios. Os princípios de educação museal da Portaria n ${ }^{\circ} 422 / 2017$, Artigo $4^{\circ}$, nivelam o museu a uma instituição de educação não formal e esclarecem a necessidade de um processo educativo organizado, de orientação teóricoprático plural, em diálogo com a sociedade, levando-se em conta uma equipe pedagógica multidisciplinar, a construção de plano educativo e cultural, na busca de assegurar o conceito de Patrimônio Integral e assim colaborar para a promoção da cidadania e do desenvolvimento regional.

A sensibilidade de uma identidade institucional voltada ao patrimônio amazônico exige uma organização de projetos que envolve uma equipe de profissionais, com captação de recursos de longo prazo para uma adequação de um museu, e não só de um laboratório, espaço este que, muitas vezes, executa suas propostas com poucos recursos.

Sobre a contribuição para a educação, pode-se explicitar, sobre a interação com o ECT Bosque da Ciência, que: a) é um ambiente para experiência de enriquecimento e potencial de interdisciplinaridade devido à caracterização das exposições; b) o uso escolar do espaço é menos frequente na educação básica do que no ensino superior, devido à necessidade de preparação da visita e possíveis recortes para o trabalho analítico, ou seja, visita a poucas exposições e mais interação dialogal e analítica sobre o objeto de aprendizagem e os conteúdos escolares; c) o papel lúdico do espaço enfatiza o aspecto estético da percepção do ambiente natural, a visualização dos animais e plantas e o impacto da imersão florestal junto às consciências dos visitantes, fazendo o que os monitores entendem como "[...] tentando despertar no visitante o interesse maior pela paisagem natural do local".

Esse entendimento do plano educativo e cultural por meio de uma equipe multidisciplinar sobre a ação educativa não é contraditório ao caráter lúdico e estético. Acredita-se que um dialogismo entre ambos é possível para a construção de um plano educativo cultural baseado no edutenimento, uma vez que devem ser observadas as características locais que tanto atraem as pessoas. Há a necessidade de tornar inteligível uma mensagem científica e ambiental, num trabalho de mútua contribuição entre laboratórios e a CAAV, neste esforço para uma versão da Amazônia a ser divulgada, uma versão que prime pela ciência e tecnologia com respeito ao ambiente.

Por fim, o Bosque da Ciência, como um exemplo de ECT de DC, permite compreender como o local está associado ao regional em presença de temas e objetos de pesquisa e de DC em nível institucional. No caso, o INPA apresenta, por meio do parque, elementos e recortes do bioma amazônico, que podem favorecer o conhecimento e o autoconhecimento que os amazônidas possuem de interagir no contexto urbano e em diálogo com informações científicas e ambientais.

\section{Agradecimento}

Este trabalho foi realizado com o apoio da Coordenação de Aperfeiçoamento de Pessoal de Nível Superior - Brasil (CAPES) -, Código de Financiamento 001. A licença de estudo em pós-graduação da Universidade Federal do Amazonas. S.D.g. 


\section{REFERÊNCIAS}

ABCMC - ASSOCIAÇÃO BRASILEIRA DE CENTROS E MUSEUS DE CIÊNCIA. Centros e museus de Ciência do Brasil 2015. Rio de Janeiro: ABCMC: UFRJ. FCC. CC; Fiocruz. Museu da Vida, 2015.

ALENCAR, Raimundo N. B.; FACHÍN-TERÁN, Augusto; BARBOSA, Ierecê. S. O processo de aprendizagem das crianças da pré-escola usando o "peixe-boi-da-amazônia" (Trichechus inunguis). In: FACHÍN-TERÁN, Augusto; SEIFFERT-SANTOS, Saulo C. Novas perspectivas de ensino de ciências em espaços não formais amazônicos. Manaus: UEA Edições, 2016.

ARAGÓN, Luis E. Amazônia, conhecerpara desenvolver e conservar: cinco temas para um debate. São Paulo: Hucitec, 2013.

AZEVEDO, Genoveva C.; HIGUCHI, Maria Inês G.; BARCELOS, Valdo. Contribuição do INPA na formação continuada de professores em educação ambiental: desafios, práticas e reflexões. Ambiente \& Educação -Revista de Educação Ambiental, s.l., v. 14, n. 1, p. 89-109, 2009.

BARCELLAR, Clarissa. A sobrevivência das espécies e o comprometimento do manejo florestal. Revista de Divulgação Científica do INPA, Manaus, v. 3, n. 7, p. 6-9, 2011.

BARDIN, Laurence. Análise de conteúdo. 4. ed. Lisboa: Edições 70, 2009.

BARROSO, Antônia L. F.; MESQUITA, Rita de Cássia G. Subsídios para a gestão de jardins botânicos no Brasil - O caso do Jardim Botânico Adolpho Ducke de Manaus. Rodriguesia, s.l., v. 65, n. 3, p. 791-805, 2014.

BASSOLI, Fernanda. O processo de apropriação da bioexposição a célula ao alcance da mão em um centro de Ciências: desafios da mediação. Ensaio Pesquisa em Educação em Ciências, Belo Horizonte, v. 15, n. 1, p. 155-174, abr. 2013.

BATISTA, Daniel; VASCONCELLOS, Regina; FACHÍN-TERÁN, Augusto. A presença do lúdico no evento Circuito da Ciência, Manaus, Amazonas, Brasil. Areté Revista Amazônica de Ensino de Ciências, Manaus, v. 8, n. 15, p. 165-174, 4 maio 2015.

BIZERRA, Alessandra; MARANDINO, Martha. Mediação em museus de Ciências: contribuições da teoria histórico-cultural. Museologia \& Interdisciplinaridade, s.l., n. 5, p. 113-130, 2014.

BONATTO, Maria Paula. Parque da ciência Fiocruz: onde a saúde é o tema. In: CRESTANA, Silvério et al. (Orgs.). Educaşão para a ciência: curso de treinamento em centros e museus de ciências. São Paulo: Editora Livraria da Física, 2001. p. 337-344.

BRASIL. Constituição Federal da República do Brasil de 1988. Promulgada em 5 de outubro de 1988. Disponível em: http://www.planalto.gov.br/ccivil_03/constituicao/constituição.htm. Acesso em: 1 maio 2020.

BRASIL. Instituto Brasileiro de Museus. Portaria n 422, de 30 de novembro de 2017 - Dispõe sobre a Política Nacional de Educação Museal - PNEM e dá outras providências. Diário Oficial da União, Brasília, p. 12-14, 2017.

BUENO, Carlos. R. Instituto Nacional de Pesquisa da Amazônia: Bosque da Ciência/Casa da Ciência. In: CRESTANA, Silvério et al. Educação para a ciência: curso de treinamento em centro e museus de ciências. São Paulo: Editora Livraria da Física, 2001. p. 357-360. 
BUENO, Wilson C. José Reis: a divulgação científica como compromisso. Comunicação \& Sociedade, s.l., v. 24 , n. 38 , p. 227-235, 2002.

CARVALHO, Tassiana F. G.; PACCA, Jesuína L. A. A aprendizagem num museu de ciência e o papel do monitor. Investigaçoes em Ensino de Ciências, Porto Alegre, v. 20, n. 1, p. 167-180, 2015.

CGEE - CENTRO DE GESTÃO E ESTUDOS ESTRATÉGICOS. Percepção Pública da C \& T no Brasil - 2019. Resumo executivo. [s.l.: s.n.], 2019.

CHAGAS, Isabel. Aprendizagem não formal/formal das Ciências. Relações entre os Museus de Ciência e as escolas. Revista de Educação, s.l., v. 3, n. 1993, p. 51-59, 1993.

COEXT. INP A Instituto Nacional de Pesquisa da Amazônia. COEXT/INPA: Manaus, 2018.

COEXT. Projeto Circuito da Ciência: a ciência mais perto de você. INPA: Manaus, 2012.

COSTA, Graziela G.; IMHOFF, Ana Lúcia; BORGES, Regina M. R. O centro de ciências de São Paulo - CECISP. In: BORGES, Regina M. R.; IMHOFF, Ana Lúcia; BARCELLOS, Guy B. Educação e cultura científica e tecnológica: centros e museus de ciências no Brasil. Porto Alegre: EDIPUCRS, 2015. p. 157-168.

CRESTANA, Silvério; HAMBURGER, Ernest W.; SILVA, Dilma N.; MASCARENHAS, Sérgio (Orgs.). Educação para a ciência: curso para treinamento em centros e museus de ciências. São Paulo: Editora Livraria da Física, 2001.

FALK, John H.; STORKSDIECK, Martin. Using the contextual model of learning to understand visitor learning from a science center exhibition. Science education, s.l., v. 89, n. 5, p. 744-778, 2005.

FLOREZ, Lilian S.; SANJAD, Nelson; OKADA, Wanda. Construção do espaço museal: Ciência, educação e sociabilidade na gênese do Parque Zoobotânico do Museu Goeldi (1895-1914). Anais do Musen Paulista: História e Cultura Material, São Paulo, v. 26, 8 out. 2018. e15. Disponível em: https://doi.org/10.1590/1982-02672018v26e15. Acesso em: 21 jul. 2021. Epub 08 Out 2018. ISSN 1982-0267.

FONSECA, Ozório M. Pensando a Amazônia. Manaus: Editora Valer, 2011.

FRIEDMAN, Alan J. The evolution of the science museum. Physics Today, s.l., v. 63, n. 10, p. 45-51, out. 2010.

HIGUCHI, Maria Inês G.; FARIAS, Maria Solange M. Pequenos guias do Bosque da Ciência: trajetória de experiência de educação ambiental com crianças na Amazônia. Manaus: INPA, 2002.

HOOPER-GREENHILL, Eilean. Learning in art museums: strategies of interpretation. In: The educational role of the museum. [s.l.: s.n.], 1999. p. 44-52.

INPA. Plano de Trabalho: Metas individuais (servidores técnicos). Manaus: CAAV, 2018a.

INPA. Plano de Trabalho - Recepção. Manaus: CAAV, 2018b.

INSTITUTO BRASILEIRO DE MUSEUS. Guia dos Museus Brasileiros/Instituto Brasileiro de Museus. Brasília: Instituto Brasileiro de Museus, 2011. 
KATZ, Phyllis et al. Professional Identity Development of Teacher Candidates Participating in an Informal Science Education Internship: A focus on drawings as evidence. International Journal of Science Education, s.l., v. 33, n. 9, p. 1169-1197, 2011. Disponível em:

https://doi.org/10.1080/09500693.2010.489928. Acesso em: 1 maio 2019.

LONDOÑO, Germán; SOLBES, Jordi; GUISASOLA, Jenaro. Aprovechamiento conceptual y actitudinal de las visitas a un parque temático. Didáctica de las ciencias experimentales y sociales, s.l., n. 23, p. 71-92, 2009 .

LOUREIRO, João J. P. Cultura Amazônica: uma poética do imaginário. 5. ed. Manaus: Editora Valer, 2015.

LUEHMANN, April. Students' Perspectives of a Science Enrichment Programme: Out-of-school inquiry as access. International Journal of Science Education, s.l., v. 31, n. 13, p. 1831-1855, 2009. Disponível em: https://doi.org/10.1080/09500690802354195. Acesso em: 1 maio 2019.

MACIEL, Hiléia M.; FACHÍN-TERÁN, Augusto. O potencial pedagógico dos espaços não formais da cidade de Manaus. Curitiba: Editora CRV, 2014.

MAIA, Beatriz; BERGAMINI, Cristiane; CASTRO, Paula D. Divulgação científica na América Latina enfrenta desafios de alcançar públicos heterogêneos. ComCiência, n. 197, p. online, 2018. Disponível em: http://www.comciencia.br/divulgacao-cientifica-na-america-latina-enfrenta-desafio-de-alcancarpublicos-heterogeneos/. Acesso em: 13 fev. 2021.

MALHEIROS, Bruno T. Metodologia da pesquisa em educaşão. Rio de Janeiro: LTC, 2011.

MARANDINO, Martha. Educação em museus: a mediação em foco. São Paulo: GEENF/FEUSP, 2008.

MARANDINO, Martha. O conhecimento biológico nas exposições de museus de ciências: análise do processo de construção do discurso expositivo. 2001. 450f. Tese (Doutorado em Educação) - Faculdade de Educação, Universidade de São Paulo, São Paulo, 2001.

MARTINS, Paula C. S. et al. O circuito da Ciência: uma estratégia desafiadora para o ensino de Ciências na região Amazônica. In: SIMPÓSIO DE EDUCAÇÃO EM CIÊNCIAS NA AMAZÔNIA, Manaus. Anais... Manaus: UEA, 2015.

MCMANUS, Paulette M. Topics in museums and science education. Studies in Science Education, s.l., v. 20, n. 1, p. 157-182, 1992.

MORENO, Tabajara. De portas abertas para a comunidade. Revista de Divulgação Cientifica do INPA, Manaus, v. 1, n. 2, p. 58-61, 2009.

MOTA, Elizângela; FACHÍN-TERÁN, Augusto; GONZAGA, Amarildo. O projeto circuito da ciência: análise do comportamento dos estudantes em relação à questão ambiental. Areté Revista Amazônica de Ensino de Ciências, Manaus, v. 8, n. 15, p. 175-181, 4 maio 2015.

NASCIMENTO, Silvana S. A relação museu e escola na prática docente: tensões de uma atividade educativa. In: DALBEN, Angela; DINIZ, Júlio; LEAL, Leiva; SANTOS, Lucíola (Orgs.). Convergências e tensões no campo da formação e do trabalho docente. Belo Horizonte: Autêntica, 2010. p. 357-369.

NORONHA, Evelyn; SANTOS, Gilmara; CARVALHO, Márcia. O Projeto Circuito da Ciência do Instituto Nacional de Pesquisas da Amazônia (INPA): contribuições para a alfabetização científica. Areté Revista Amazônica de Ensino de Ciências, Manaus, v. 6, n. 11, p. 179-194, 2013. 
NRC - NATIONAL RESEARCH COUNCIL. Learning Science in Informal Environments: People, Places, and Pursuits. In: BELL, Philip et al. (Eds.) Washington-DC: The Nacional Academies Press, 2009.

PADILLA, Jorge. Museos y Centros de Ciencia en México. In: CRESTANA, Silvério et al. (Orgs.). Educação para a ciência: curso de treinamento em centros e museus de ciências. São Paulo: Editora Livraria da Física, 2001. p. 41-58.

PALHARES, José A. Reflexões sobre o não-escolar na escola e para além dela. Revista Portuguesa de Educação, s.l., v. 22, p. 53-84, 2009.

PASCUAL, Morentin M.; ARANZABAL, Jenaro G. La visita a un museo de ciencias en la formación inicial del profesorado de Educación Primaria. Revista Eureka sobre Enseñanza y Divulgación de las Ciencias, s.l., v. 11, n. 3, p. 364-380, 2014.

PAVÃO, Antonio C.; LEITÃO, Ângela. Hands-on? Minds-on? Hearts-on? Social-on? Explainers-on! In: MASSARANI, Luisa (Org.). Diálogos \& ciência: mediação em museus e centros de ciência. Rio de Janeiro: Casa de Oswaldo Cruz: Fiocruz, 2007. p. 40-47.

POLINO, Carmelo. Las encuestas de percepción pública de la ciencia en América Latina: estructura, evolución y comparabilidad. In: MASSARANI, Luisa (Ed.). RedPOP: 25 años de popularización de la ciencia en América Latina. Rio de Janeiro: Fiocruz: RedPOP; Montevidéu: Unesco, 2015. p. 95-108.

QUEIRÓZ, Glória et al. Construindo saberes da mediação na educação em museus de ciências: o caso dos mediadores do museu de astronomia e ciências afins/ Brasil. Revista Brasileira de Pesquisa em Educação em Ciências, s.l., v. 2, n. 2, p. 77-88, 28 nov. 2011.

RICHARDSON, Roberto J. Pesquisa social e técnicas. 3. ed. 14. reimp. São Paulo: Atlas, 2012.

RODARI, Paola; MERZAGORA, Matteo. Mediadores em museus e centros de ciência: Status, papéis e treinamento. Uma visão geral europeia. In: Diálogos \& Ciência: mediação em museus e centros de Ciência. Rio de Janeiro: Museu da Vida: Casa de Oswaldo Cruz: Fiocruz, 2007. p. 7-20.

SABIESCU, Amalia; CHARATZOPOULOU, Katerina. The Museum as Ecosystem and Museums in Learning Ecosystems. In: SPRINGER (Ed.). Museum Experience Design. [s.1.] Springer, Cham, 2018, p. $325-345$.

SANJAD, Nelson; OREN, David C.; SILVA JUNIOR, José S.; HOOGMOED, Marinus S.;

HIGUCHI, Horácio. Documentos para a história do mais antigo jardim zoológico do Brasil: o Parque Zoobotânico do Museu Goeldi. Bol. Mus. Para. Emílio Goeldi. Cienc. Hum, Belém, v. 7, n. 1, p. 197-258, 2012.

SEIFFERT-SANTOS, Saulo C. O discurso expositivo de um espaço amazônico de educação não formal em Ciência e Tecnologia: o caso do Bosque da Ciência. 2020. 338f. Tese (Doutorado em Educação em Ciências) Programa de Pós-Graduação em Educação em Ciências e Educação Matemática, Unioeste, Cascavel, 2020a.

SEIFFERT-SANTOS, Saulo C. Uma visão sobre os museus de ciências como espaços não formais: o Bosque da Ciência um exemplo amazônico. REAMEC - Rede Amarônica de Educação em Ciências e Matemática, Manaus, v. 8, n. 3, p. 415-434, 1 out. 2020b. 
SEIFFERT-SANTOS, Saulo C.; CUNHA, Márcia B. A pesquisa em espaços de educação não formal em Ciências na Região Norte: o caso do Bosque da Ciência. Amazônia RECM, Belém, v. 14, n. 32, p. 160-173, 2018.

SEIFFERT-SANTOS, Saulo C.; CUNHA, Márcia B. A tradição de pesquisa segundo Laudan em educação em espaços não formais num evento de ensino de Ciências. Góndola, Enseñanza y Aprendizaje de las Ciencias, s.l., v. 14, n. 1, p. 88-107, 2019.

SEIFFERT-SANTOS, Saulo C.; CUNHA, Márcia B. O Instituto Nacional de Pesquisas da Amazônia (INPA) e o seu papel na popularização da Ciência em Manaus. História da Ciência e Ensino: construindo interfaces, v. 22, p. 67-85, 2020. Disponível em:

https://revistas.pucsp.br/index.php/hcensino/article/view/49326. Acesso em: 27 dez. 2020.

SEIFFERT-SANTOS, Saulo C.; FACHÍN-TERÁN, Augusto. O uso da expressão espaços não formais no ensino de Ciências. Areté Revista Amazônica de Ensino de Ciências, Manaus, v. 6, n. 11, p. 01-15, 2013.

SILVA, Glauciane S.; SHIMADA, Marly S.; ALENCAR, Mary S. D.; FACHÍN-TERÁN, Augusto. Participação dos estudantes do ensino fundamental no circuito da ciência e aprendizagem dos conteúdos sobre o ensino de ciências. Areté Revista Amazônica de Ensino de Ciências, Manaus, v. 8, n. 15, p. 140-153, 2015.

SUESCUN FLÓREZ, Lílian; MORAIS, Silvilene; SCHEINER, Tereza C.; REIS, Maria Amélia. Qual o discurso privilegiado nos jardins botânicos? tensões e aproximações entre linguagem científica e linguagem leiga. Revista Eletrônica do Programa de Pós-Graduação em Museologia e Patrimônio, s.l., v. 5, n. 1, p. 3-28, 2012.

VOLÓCHINOV, Valentin N.; BAKHTIN, Mikhail M. [1927]. O freudismo. 2. ed. São Paulo: Perspectiva, 2017.

WAGENSBERG, Jorge. Principios fundamentales de la museología científica moderna. B.MM Cuaderno Central, s.l., n. 55, 2001. Disponível em:

http://www.bcn.cat/publicacions/bmm/quadern_central/bmm55/5.Wagensberg.pdf. Acesso em: 18 jun. 2019.

\section{CONTRIBUIÇÃO DOS AUTORES}

Autor 1 - Coordenador do projeto, coleta de dados, análise dos dados e escrita do texto.

Autora 2 - Orientadora do projeto, participação ativa na análise dos dados e revisão da escrita final.

\section{DECLARAÇÃO DE CONFLITO DE INTERESSE}

Os autores declaram que não há conflito de interesse com o presente artigo.

Submetido: $13 / 02 / 2021$

Aprovado: 08/09/2021 